\title{
Non-Bunching at Kinks and Notches in Cash Transfers in the Netherlands*
}

\author{
Nicole Bosch ${ }^{\dagger}$ Egbert Jongen ${ }^{\ddagger}$ \\ Wouter Leenders ${ }^{\S}$ Jan Möhlmann
}

April 2019

\begin{abstract}
We study the behavioural responses to kinks and notches in the Dutch system of cash transfers, using data on the universe of Dutch households for the period 2007-2014. We typically do not find statistically significant evidence of bunching around kinks or notches, neither in income nor in wealth. This finding is robust across different household types and modes of employment. We consider potential mechanisms that can explain this apparent lack of bunching.
\end{abstract}

JEL codes: D83, H24, H31

Keywords: Bunching, cash transfers, income, wealth

${ }^{*}$ We have benefited from comments and suggestions by the editor Claus Thustrup Kreiner, two anonymous referees, Michael Best, Matthijs Jansen, Henrik Kleven and seminar and conference participants at CPB Netherlands Bureau for Economic Policy Analysis, the NED 2017 in Amsterdam, the SMYE 2018 in Palma de Mallorca and the IIPF 2018 in Tampere. Furthermore, we thank Patrick Koot and Marente Vlekke for their assistance in calculating the effective marginal tax rates using MIMOSI, Statistics Netherlands for access to the microdata (Project 8074) and Reinder Lok of Statistics Netherlands for additional information on the microdata. Remaining errors are our own.

${ }^{\dagger}$ Dutch Tax Authority. E-mail: nm.bosch@belastingdienst.nl.

${ }^{\ddagger}$ CPB Netherlands Bureau for Economic Policy Analysis, Leiden University and IZA. E-mail: e.l.w.jongen@cpb.nl.

$\S$ University of Zurich. Corresponding author. University of Zurich, Schönberggasse 1, 8001 Zürich. E-mail: wouter.leenders@econ.uzh.ch.

ॠCPB Netherlands Bureau for Economic Policy Analysis. E-mail: j.l.mohlmann@cpb.nl. 


\section{Introduction}

Cash transfers play a key role in the system of income redistribution in developed economies. When using cash transfers, governments face a trade-off between equity and efficiency (Mirrlees, 1971). The effective marginal tax rates that result from phasing out income support distorts the choices of households. In the Netherlands, the phasing out of the housing benefit alone adds between 20 and 40 percentage points to the effective marginal tax rates of low income households. In addition, effective marginal tax rates exceed $100 \%$ at the eligibility cutoff where the housing benefit suddenly drops to zero. As such, the housing benefit's notched structure has been blamed for disincentivising low-income households (Commissie Inkomstenbelasting en Toeslagen, 2013). Obtaining a good empirical understanding of the behavioural responses to the phase out of targeted cash transfers is therefore of key interest to policy makers.

In this paper we estimate the behavioural responses to incentives produced by the kinked and notched structure of the Dutch transfer system. These cash transfers depend on the level of taxable income and wealth. We consider whether the kink and notch of the housing benefit, the benefit for children and the benefit for health care lead to bunching in the income and/or wealth distribution.

The bunching approach exploits excess density mass around discontinuities in either the slope (kinks) or the level (notches) of the budget set to identify behavioural responses (Kleven, 2016). For the empirical analysis we construct an administrative dataset for the universe of Dutch households for the period 2007-2014. Specifically, we link confidential data sets from Statistics Netherlands on taxable income and taxable wealth for households with data on the take-up and level of cash transfers 
and data on household characteristics. We consider bunching due to the kink and notch of the housing benefit (Huurtoeslag in Dutch) in the taxable income distribution of tenants. The kink in the housing benefit leads to a substantial rise in effective marginal tax rates in the order of 20 to 40 percentage points, while the notch leads to a sizeable drop in net income of up to 1,750 euro at the threshold. Furthermore, we consider bunching in taxable wealth due the notch of the health care benefit (Zorgtoeslag) and child benefit (Kindgebonden Budget) for low income households. The size of this notch is substantial, in particular for households with dependent children, and can amount to thousands of euros. We consider differences in responses by household types, and by modes of employment (employee vs. self-employed). Furthermore, we compare the bunching around kinks and notches of cash transfers with bunching around tax bracket thresholds. Finally, we study the dynamics of the taxable income and taxable wealth distribution of households around the notch. Here we are particularly interested in whether there is gradual learning or that households remain in dominated regions for multiple years.

Our main findings are as follows. First, we generally find no evidence of bunching in taxable income at the kinks and notches in the housing benefit scheme, independent of household type or mode of employment. The finding that households with self-employed individuals do not bunch around kinks and notches of targeted cash transfers contrasts with our findings that these households do bunch around tax bracket thresholds. Second, we find no evidence of bunching in taxable wealth for the notch in the health care scheme and child benefit scheme. Taxable wealth (measured on the 1st of January) is arguably more easy to manipulate than taxable income (e.g. by buying a large television set in December), but we do not observe bunching at the notch. Third, we do not find evidence of gradual learning by house- 
holds, as households remain in dominated regions for several years. More generally, we find no evidence of different income and wealth dynamics to the 'left' and to the 'right' of notches.

The lack of bunching could be a result of either a low structural elasticity or high frictions. However, Bastani and Selin (2014) shows that in the absence of frictions, even small elasticities $(0.01,0.1)$ lead to substantial amounts of bunching. We also show that there are strong financial incentives to bunch, even after taking into account non-take-up. Any explanation for little or no bunching will thus have to carefully consider the role of frictions that prevent households from optimally choosing their level of taxable income. We cannot directly test the importance of adjustment costs as we lack substantial variation in the institutional setup (e.g. no large shifts in the location of kinks or notches). In any case, adjustment costs are unlikely to be the sole explanation for the observed lack of bunching. Since we do not observe bunching for the self-employed nor for wealth, where adjustment costs are arguably less important, we argue that a lack of salience and inattention likely play an important role. Our finding that a substantial fraction of households remains in the dominated region for several years adds support to this explanation, as does the observation that the self-employed bunch before tax bracket thresholds but not for kinks and notches in income-dependent cash transfers. On the upside, these results suggest that the efficiency losses from targeted cash transfers may be limited, at least to the extent we can measure them close to the kink or notch. ${ }^{1}$ In particular, it appears that the behavioural responses to high marginal tax rates induced by cash transfers are lower than responses to marginal tax rates induced by the statutory tax

\footnotetext{
${ }^{1}$ Interestingly, Jones and Marinescu (2018) study the labour market effects of universal cash transfers paid out by the Alaska Permanent Fund and similarly find no negative effects on employment.
} 
rates. On the downside, a substantial fraction of low-income households do not take up the cash transfers designed for them. Furthermore, large kinks and notches imply large differences in the implicit social welfare weights for households that differ only slightly in their taxable income or wealth, which is inconsistent with a well-behaved social welfare function (Jacobs et al., 2017).

We make a number of contributions to the existing literature. Firstly, we contribute to the bunching literature by adding a detailed case of income-dependent cash transfers, that generate kinks and notches that are larger than jumps in statutory tax rates. ${ }^{2}$ A common finding in the bunching literature is that observed elasticities of taxable income are near zero, a factor of magnitude lower than 'conventional' estimates using the Gruber-Saez methodology or difference-in-differences estimators (Saez et al., 2012; Kleven and Schultz, 2014). ${ }^{3}$ One explanation for the low elasticities implied by bunching is that optimisation frictions prevent individuals from bunching (Chetty et al., 2011; Chetty, 2012). Accounting for optimisation frictions, such as hours constraints, inattention, or inertia, is a complex issue and both parametric and non-parametric techniques have been used to uncover the degree to which such optimisation frictions play a role. The parametric approach has been pursued by Chetty et al. (2011) and Gelber et al. (2017), but such estimates face the risk of being dependent on the particular parametric specification. An alternative

\footnotetext{
${ }^{2}$ The bunching approach has already been applied to policies in the US (Saez, 2010), Denmark (Chetty et al., 2011; Kleven et al., 2011; Le Maire and Schjerning, 2013), the UK (Adam et al., 2017), Ireland (Hargaden, 2015), Sweden (Bastani and Selin, 2014), and to tax rates in the Netherlands (Dekker et al., 2016; Bettendorf et al., 2016).

${ }^{3}$ A similar result is found for the Netherlands. Jongen and Stoel (2016) exploit variation induced by the 2001 tax reform in the Netherlands, following the Gruber-Saez methodology (Gruber and Saez, 2002), and find a long run elasticity of 0.24. Dekker et al. (2016) apply the kink-based bunching approach to tax bracket thresholds in the Netherlands and find small elasticities, close to zero for singles and single parents. Couples display larger bunching, but this is due to the shifting of tax deductions from the partner with a lower marginal tax rate to the partner with a higher marginal tax rate (the Netherlands has an individualised tax system).
} 
approach is to compare bunching by salaried workers and self-employed, where selfemployed arguably face lower frictions in adjusting their taxable income. Whereas salaried workers typically do not bunch before tax bracket thresholds, self-employed are usually found to do so. We find that self-employed bunch before tax bracket thresholds in the Netherlands, but do not bunch before kinks in the cash transfer system. This is consistent with another explanation that is offered in the bunching literature, a lack of salience. Differences in knowledge about the structure of benefits have been shown to have a substantial effect on the size of the behavioural response (Chetty et al., 2013). Our results are consistent with an important role for a lack of salience for cash transfers: we find substantial non-take-up of these benefits and we also find that households in dominated regions do not 'learn' about their financial incentives over multiple periods of time. Secondly, we contribute to the literature studying notches, which typically provide stronger financial incentives to bunch. The analysis by Kleven and Waseem (2013) focuses on notches in the Pakistani income tax and finds large observed bunching but a modest structural elasticity. Adam et al. (2017) apply the Saez-Kleven-Waseem technique to kinks and notches in the UK. Their kink-based estimates are small, while the unattenuated notch-based elasticities are an order of magnitude larger due to a high fraction of non-responders in the dominated region. Hargaden (2015) considers notches in Ireland and finds that the fraction of non-responders in the dominated region is high and strongly cyclical, just below $95 \%$ in good years and over $99 \%$ in bad years, suggesting that observed elasticities are seriously attenuated by optimisation frictions. We generally find no evidence of lower densities to the right of the notch, implying a fraction of non-responders close to $100 \%$. Finally, we contribute to the literature that uses quasi-experimental evidence to analyse the effect of wealth taxes on wealth 
accumulation, by considering the wealth threshold (an implicit tax on wealth) for health care and child benefits. So far the evidence has been mixed, with Zoutman (2015), Seim (2017) and Jakobsen et al. (2018) finding modest elasticities in the Netherlands, Sweden and Denmark and Brülhart et al. (2016) documenting a larger net-of-tax elasticity in Switzerland. Finding no response to the wealth threshold introduced in 2013, our results lie closer to the estimates of the former group.

The paper is organised as follows. Section 2 discusses the theory underlying the bunching approach and the empirical methodology. Section 3 describes the institutional context and data sets used. Section 4 presents the empirical results. Section 5 discusses our findings. Section 6 concludes. An appendix contains supplementary material.

\section{Theory and methodology}

There are a number of potential mechanisms that may explain whether and to what extent we observe bunching at kinks and notches in the tax and transfer system. ${ }^{4}$ Below we first outline the theoretical case of bunching when there are no (optimisation) frictions. Next, we consider a number of mechanisms that may limit the extent to which we observe bunching in the data, including optimisation frictions.

\subsection{Bunching in the absence of frictions}

In conventional models of taxation the combination of a smooth ability distribution $f(n)$, smooth preferences, and a smooth tax schedule (i.e. no kinks or notches)

\footnotetext{
${ }^{4}$ An extensive review of the bunching literature can be found in Kleven (2016).
} 
results in a smooth pre-tax earnings distribution $h_{0}(z)$. In such models, households have preferences over effort, where individuals with a higher ability $n$ have to put in less effort to generate a given pre-tax income $z$, and consumption, which for simplicity is assumed to equal post-tax income $z-T(z)$ with $T($.$) denoting taxes.$ Utility is a function of post-tax income and effort: $u(z-T(z), z / n)$.

These models predict that the introduction of kinks, discontinuous increases in the marginal tax rate, and notches, discontinuous changes in the average tax rate, lead to bunching. In the case of (convex) kinks, a sudden increase in the marginal tax rate, households move from the right of the kink and 'bunch' at the kink point (Saez, 1999, 2010; Chetty et al., 2011). In the case of notches, post-tax income drops when pre-tax income increases such that it passes the notch point. Households to the right of the notch move to the notch point and leave a hole in the distribution just above the notch. When this hole is not entirely empty, the density of households in the area just above the notch can in principle be used to measure optimisation frictions (Kleven and Waseem, 2013). ${ }^{5}$ Seim (2017) provides an analogous model to study bunching in the wealth distribution. In this model, households optimally choose their level of taxable wealth and when faced with a change in the average or marginal tax rate on wealth bunch accordingly.

\footnotetext{
${ }^{5}$ In addition to convex kinks and notches, the housing benefit that we study also introduces a non-convex kink. Theoretically, such kinks lead to holes in the income distribution around the kink. Emperically, however, no such holes have been found. While we do not report these results in this paper directly, we did not find any holes around non-convex kinks either.
} 


\subsection{Mechanisms that may limit the extent of bunching}

There are a number of potential mechanisms that may limit the extent of bunching we observe in the data, which we discuss below. ${ }^{6}$

One reason why bunching could be limited is that the elasticity of income with respect to the (net-of-)tax rate is low. However, even for relatively low elasticities, bunching in the absence of frictions is still predicted to be large, as demonstrated by Bastani and Selin (2014).

Another reason why bunching may be limited is when the change in the tax rate (compared to the level of the net-of-tax rate) is relatively small (Saez, 1999). However, below we will show that the housing benefit causes a large change in the effective marginal tax rate at the kink, and even more so at the notch. An important caveat here is that the change in the tax rate is partly muted by the fact that there is substantial non-take-up of the housing benefit. Indeed, when we discuss the institutional context and data we show that there is substantial non-take-up of the housing benefit, in particular close to the notch (and consider plausible explanations for the substantial non-take-up).

Adjustment costs may limit the extent to which individuals can optimise their income in the face of large effective marginal tax rates (Attanasio, 2000). This may be particularly relevant for tenants, many of them employees who have limited control over their wage scale and exact working hours (Matikka and Kosonen, 2019). In addition, they are less likely to use deductions to manipulate their taxable income (CPB, 2016). ${ }^{7}$ These adjustment costs become even more relevant when we consider

\footnotetext{
${ }^{6}$ For a discussion of potential mechanisms that may mitigate the extent of bunching we observe see e.g. Chetty (2012), Kleven (2016), Matikka and Kosonen (2019), Søgaard (2019).

${ }^{7}$ These adjustment costs also include the cost of taking up the benefit once one becomes eligible. In our case, however, these costs are somewhat contained by the fact that households can apply
} 
that there are substantial income dynamics, as we will show below, so that the return period on the incurred adjustment costs becomes relatively short. Adjustment costs will typically lead to 'fuzzy' bunching in the case of a kink, where the excess mass occurs not solely at the kink, but also close to the kink (Søgaard, 2019), and may result in a positive density in dominated regions (Kleven, 2016).

Inattention may limit the extent to which individuals are aware of the utility loss from a suboptimal choice (Sims, 2003; Gabaix, 2017). Information costs may prevent individuals to be aware of all the details of the tax and transfer system. This seems particularly relevant for our case, as the details of the transfer system are complicated. For example, the housing benefit of a particular household depends non-linearly on the household's rent, income and wealth in addition to the exact household composition. Inattention is also expected to lead to 'fuzzy' bunching rather than sharp bunching (Søgaard, 2019). We consider whether we observe gradual learning, since individuals may become more knowledgeable of the tax and transfer system over time. Gradual learning may explain why individuals initally locate in regions with high marginal tax rates or dominated regions, and then (are more likely to) move out of these regions in later periods. ${ }^{8}$

After we present the results we reconsider the potential mechanisms at work, and discuss which mechanisms are most likely to play a role in the lack of bunching we observe.

\footnotetext{
for benefits online.

${ }^{8}$ Søgaard (2019) also considers price misperception as a potential optimisation friction, where e.g. individuals mistakingly use average tax rates instead of marginal tax rates to calculate the net gain from earning more or less income. This seems less relevant for our case.
} 


\subsection{Estimation}

In estimating the amount of bunching we closely follow Best and Kleven (2018). We group households in $€ 100$ bins and construct the counterfactual (i.e. absent the kink or notch) by fitting a polynomial to the actual distribution, excluding the area directly around the kink or notch ('omitted range'). Concretely, we run the regression

$$
c_{i}=\sum_{j=0}^{q} \beta_{j}\left(z_{i}\right)^{j}+\sum_{y^{-}}^{y^{+}} \gamma \mathbf{I}\{i=k\}+\varepsilon_{i},
$$

where $c_{i}$ is the number of households in bin $i, z_{i}$ is the distance between bin $i$ and the kink or notch point, $q$ is the order of the polynomial, and $\varepsilon_{i}$ is the residual. The second term of this regression includes a number of dummies for whether a bin is in the omitted range $\left(y^{-}, y^{+}\right)$. The counterfactual is then defined as the predicted values $\hat{c}_{i}$ from equation 1 when excluding the omitted range dummies. When there is clear bunching, the values of $y^{-}$and $y^{+}$are usually determined by visual inspection. In our case, there are no obvious candidates since in most cases we do not observe bunching. ${ }^{9}$ Bunching, $\hat{B}$, is defined as the difference between the number of actual and counterfactual households in the area just before the kink or notch, $\hat{B}=\sum_{i=y^{-}}^{y^{*}}\left(c_{i}-\hat{c}_{i}\right)$, where $y^{*}$ is the kink or notch point. We report estimates for $\hat{b}$, which divides the amount of bunching by the density just before the kink or notch, $f_{0}: \hat{b}=\hat{B} / f_{0}$. Standard errors are obtained by bootstrapping the procedure 200 times.

Unlike Best and Kleven (2018), we do not include fixed effects to control for round number bunching. The reason is that most of our kinks and notches are no

\footnotetext{
${ }^{9}$ In our results, we have set $y^{-}$equal to $€ 1,000$ to the left of the kink or notch and $y^{+}$equal to $€ 4,000$ to the right of the kink or notch. Changing the values of $y^{-}$and $y^{+}$, however, leaves our estimates essentially unchanged.
} 
round numbers and more generally there appears to be no round number bunching in the income and wealth concepts relevant to our case.

\section{Institutional context and data}

\subsection{Income-dependent benefits}

Redistribution in the Netherlands takes the form of a wide array of progressive taxes and benefits (Commissie Inkomstenbelasting en Toeslagen, 2013). While most of these schemes induce kinks across the distribution, we focus on those that also create notches: the housing benefit (Huurtoeslag), health care benefit (Zorgtoeslag), and child benefit (Kindgebonden Budget).${ }^{10}$ All three of these benefits create wealth notches, while the housing benefit also creates an income notch.

\subsubsection{Housing benefit}

The housing benefit is a means-tested benefit for tenants. Of the 7.4 million households in the Netherlands in 2014, 3.2 million rented their accommodation and almost $40 \%$ of those households received the housing benefit (Statistics Netherlands, 2016). The average annual benefit paid out to the 1.2 million receiving households was 2,100 euro (Statistics Netherlands, 2016).

Eligibility is determined by a household's income, wealth and rent. Below we explain the housing benefit in 2014 and for people with an age above 23 and below 65. ${ }^{11}$ The income condition states that income cannot be above 21,600 euro for

\footnotetext{
${ }^{10}$ There also exists a cash transfer that is conditioned on the use of formal child care (Kinderopvangtoeslag). We ignore this transfer as it does not generate sharp kinks or notches in household income or wealth.

${ }^{11}$ Different rules applied for younger and older people.
} 
single-person households and 29,325 euro for multi-person households. The relevant income concept is the sum across all household members of all income reported for income tax purposes after deductions. For most households that are eligible for the housing benefit, this will be equal to the fiscal wage, which can be observed on the monthly income statement of employees. For self-employed, profits instead of wages are used. The housing benefit is paid out as an advance, based on the expected fiscal income in the current year. Households can self-report their expected income, otherwise it will be based on income in previous years. When the household's actual fiscal income is known at the end of the year, the advance is subtracted from the correct housing benefit and the difference is settled with the household. Households can apply for the housing benefit during the year as well as afterwards.

The wealth condition states that net wealth on January 1st cannot exceed 21,139 euro per person. The relevant concept of net wealth is based on the definition of wealth in the income tax. This definition includes financial assets such as savings and portfolio investments. Financial institutions report these financial assets directly to the Dutch tax authority. Households have to self-report financial assets or obligations that are not registered by financial institutions, like cash, loans, or real estate (other than the primary home). The fiscal definition of wealth excludes pension assets, durable goods like cars, owner-occupied housing and fiscally associated debt. Other debts over 2,900 euro can be subtracted.

Finally, the rent condition states that total rent cannot exceed 699.48 euro per month and must lie above the so called "basic rent". ${ }^{12}$ The basic rent increases

\footnotetext{
${ }^{12}$ There is an exception for households whose rent was initially below the maximum rent threshold, but rises in subsequent years. These households do not lose their right to housing benefits as long as they do not move.
} 
with income and is equal to $a \cdot Y^{2}+b \cdot Y+c$, with a minimum of 226.98 euro. $^{13}$ If these three conditions are satisfied, the tenant is eligible for the housing benefit. The size of the benefit depends on household type, income $Y$ (as it determines the basic rent), and rent $R .{ }^{14}$ Note that the housing benefit only subsidises the part of the rent above the basic rent. Since a higher income increases the basic rent it thereby reduces a household's housing benefits.

Figure 1 illustrates how the housing benefit depends on a household's income, clearly showing the notch in the form of the vertical segment. The phase out region starts at an income level of 15,025 euro for single-person households and 19,400 euro for multi-person households. At these income levels the sudden start of the phase out creates a convex kink. The effective marginal tax rate increases gradually up to the point where income is such that basic rent, $R_{B}(Y)$, surpasses the first rent threshold $R_{1}$. After this point, a household loses only 0.65 euro (instead of 1 euro) in benefits for every 1 euro rise in basic rent so that the additional effective marginal tax rate suddenly falls, creating a nonconvex kink. This is illustrated in Figure 2. Figure 1 and Figure 2 are based on a monthly rent of 699 euro, which is the highest possible rent without losing eligibility. the notch will be lower or not applicable for households with a lower rent, which is illustrated in Figure A.1 in the supplementary material.

\footnotetext{
${ }^{13}$ For single-person households, $a=0.000000744662$ and $b=0.002091986183$, while for multiperson households, $a=0.000000419824$ and $b=0.002140982472$. For all households, $c=27.44$.

${ }^{14}$ First, for any rent $R$ that lies above the basic rent $R_{B}(Y)$, there is full compensation for the interval between the basic rent and the first threshold, $\left[R_{B}(Y), R_{1}\right]$. Second, if a household's rent exceeds $R_{1}$ the portion above $R_{1}$ and below the second threshold $R_{2}$, which depends on household type, is subsidised at a rate of $65 \%$. $R_{1}$ is equal to 389.05 euro in 2014 . Households that consist of at most two members face an $R_{2}$ of 556.82 euro, while for larger households, $R_{2}$ equals 596.75 euro. Finally, in the case of single-person households there is an additional subsidy of $40 \%$ on the part of the rent that lies on the interval $\left[R_{2}, R_{\max }\right]$.
} 
Figure 1: Housing benefit in 2014 as a function of income and household type

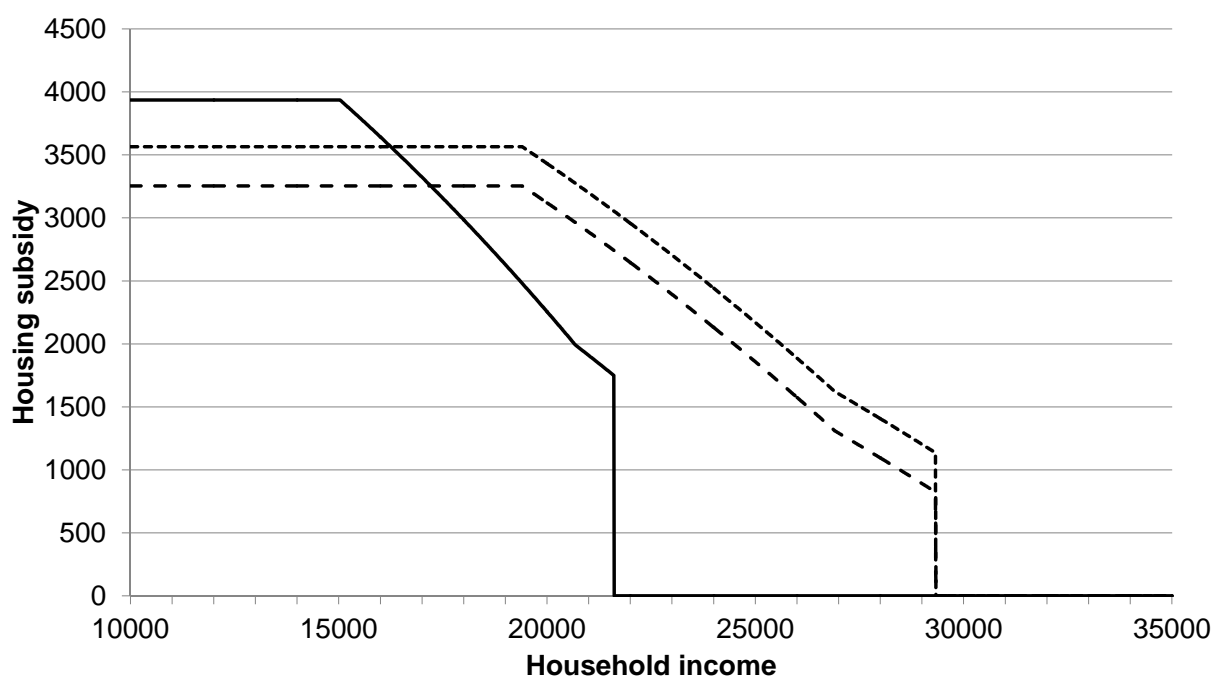

-One person - - Two persons --- Three or more persons

Notes: This graph shows the amount of annual housing benefit received in 2014 by different household types as a function of annual income. This graph applies to households with a monthly rent of 699 euro, which is the highest possible rent without losing eligibility. 
Figure 2: Additional marginal tax rate in 2014 due to the housing benefit

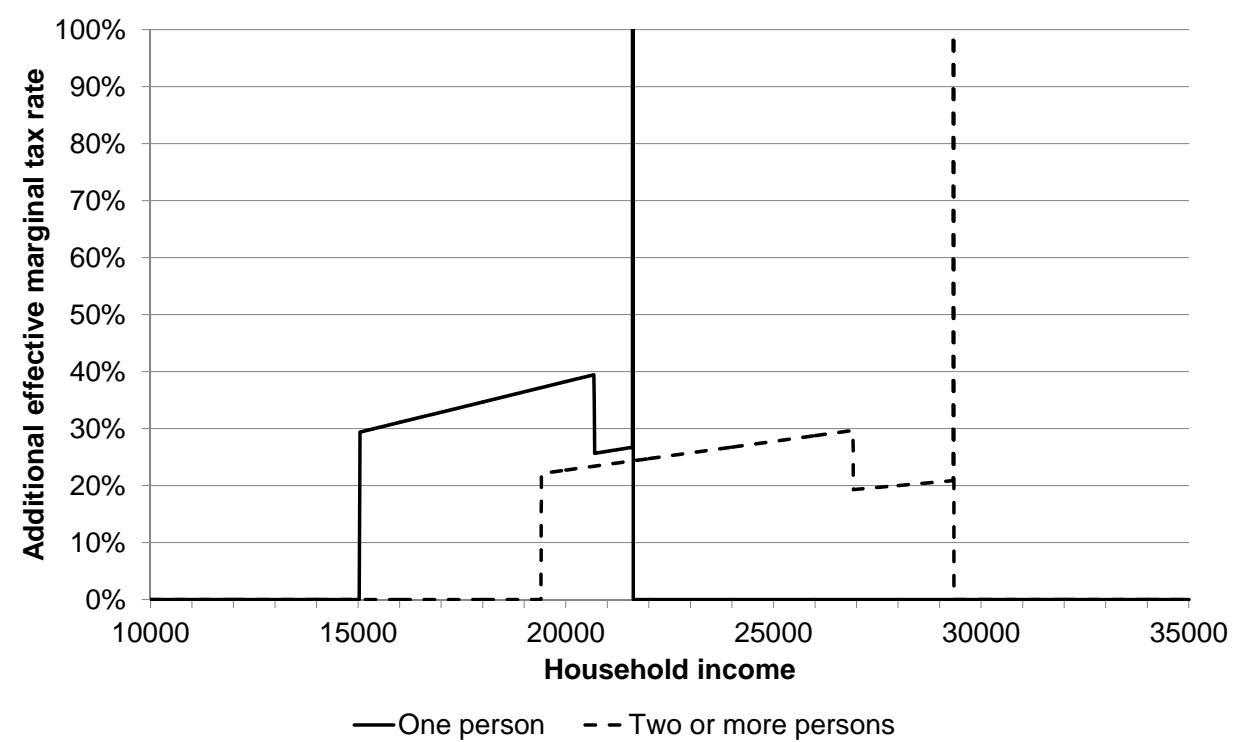

Notes: This graph shows the implicit additional marginal tax rate in 2014 for different household types with a monthly rent of 699 euro, induced by the phase out of the housing benefit, defined over 1 euro intervals.

\subsubsection{Health care benefit and child benefit}

The health care benefit and the child benefit are means-tested benefits, for which eligibility is conditional on income and net wealth. The relevant concepts for income and net wealth are identical to that of the income tax and housing benefit. The health care benefit and child care benefit are also paid out as an advance during the year, based on expected fiscal income, and settled afterwards. The health care benefit is aimed at adults covered by health insurance, which is mandatory in the Netherlands. In 2014, the income threshold is 28,482 euro for singles and 37,145 for couples. The threshold for net wealth on January 1st is 102,499 for singles and 123,638 for couples.

The size of the annual health care benefit depends only on income and is equal 
to $a-b \cdot(Y-c)$, with a maximum of 865 euro for singles and 1,655 for couples. ${ }^{15}$ This implies that the health care benefit increases the effective marginal tax rate by $9.118 \%$ on the interval 19,253 - 28, 482 euro for singles and on the interval $19,253-37,145$ euro of joint income for couples. ${ }^{16}$

The child benefit is aimed at households with one or more children with an age below 18. In 2014, households lose eligibility if their net wealth on January 1st exceeds 102,499 for singles or 123,638 for couples. These are the same net wealth thresholds as for the health care benefit. This means that the financial incentive of staying below this threshold is amplified if the household is eligible for both benefits. The maximum child benefit depends on the number of children and their age. For households with one child, the maximum child benefit is 1,017 euro. The maximum is increased by 563 euro for the second child, by 183 euro for the third child and by 106 euro for each additional child. If children are older than 12, the maximum is further increased. The child benefit is reduced by $7.6 \%$ of each additional euro income earned above 26,147. The phase out region of the child benefit depends on the maximum benefit and therefore depends on the number and ages of children.

\subsection{Effective marginal tax rates}

Figure 3 shows the effective marginal tax rates (EMTRs) for tenants (below the retirement age) in 2014, and the underlying components. In the empirical analysis below we will also show density plots for the whole group of tenants. It is important to emphasize that not all tenants qualify for the housing benefit (for example because

\footnotetext{
${ }^{15}$ For singles $a=865$ and for couples $a=1,655$. For all households, $b=0.09118$ and $c=19,253$.

${ }^{16}$ Note that this also implies a small notch at the income threshold, since the size of the health care benefit is still 24 euro just below the income threshold. However, we believe that this notch is too small to generate observable bunching.
} 
their rent is too high), and not all tenants that do qualify for the housing benefit take up the housing benefit. Hence, the kink and notch in the housing benefit apply only to part of the households shown in Figure 3. However, the kink and the notch of the housing benefit are clearly visible.

We show EMTRs for singles, single parents, single-earner couples without children, single-earner couples with children, dual-earner couples without children and dual-earner couples with children. We distinguish these groups because benefits differ for these groups. We plot the average EMTRs by income bins of 500 euro of taxable household income, the relevant income concept for the benefits we consider. We calculate the EMTRs using the advanced tax-benefit calculator MIMOSI of CPB. ${ }^{17}$ Specifically, we calculate the EMTRs corresponding to an increase in gross personal income of $3 \%$. The EMTRs account for the statutory tax bracket rates ${ }^{18}$, the benefits described in the previous subsection, the 'general' tax credit (Algemene Heffingskorting) and the earned income tax credit (Arbeidskorting). ${ }^{19}$

For childless singles we observe that the phase in of the earned income tax credit reduces EMTRs up to a gross income of 19 thousand euro. The phase out of the housing benefit substantially increases EMTRs over the income range from 15 to 22 thousand euro, with a 'spike' at the end where we have the notch. The phase out of the health care benefit increases EMTRs somewhat between 19 and 28 thousand

\footnotetext{
${ }^{17}$ MIMOSI uses data from the Income Panel of Statisctis Netherlands for 2010 (approximately 100,000 individuals), uprated by CPB to the year 2014, see Koot et al. (2016).

${ }^{18}$ Which in 2014 were $36.25 \%$ for the income bracket $0-19,645,42 \%$ for the income bracket $19,645-56,531$ and $52 \%$ for the income bracket above 56,531 .

${ }^{19}$ The general tax credit is 2,103 euro which falls to 1,366 on the income interval $19,645-56,495$. The earned income tax credit builds up from 0 euro to 161 euro at a rate of $1.81 \%$ of each additional euro earned on the income interval $0-8,913$ and from 163 euro to 2,097 euro at a rate of almost $20 \%$ on the income interval 8,913-19,253 euro. On these intervals the earned income tax credit has a negative contribution to the EMTR. The earned income tax credit has a positive contribution to the EMTR on the income interval 40,721-83,971 euro, where it is reduced by $4 \%$ of each additional euro earned from 2,097 euro to 367 euro.
} 
Figure 3: Average EMTRs tenants by household income

(a) Childless singles

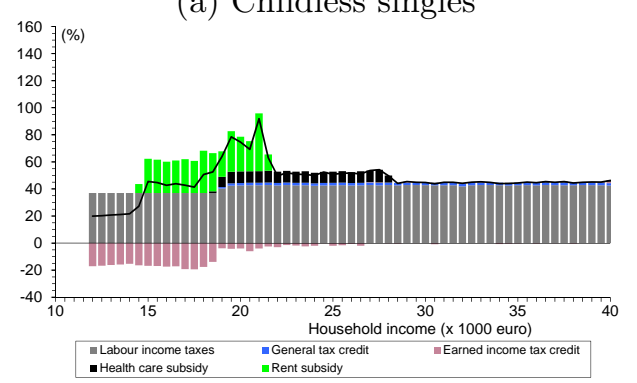

(c) Single-earner couples without children

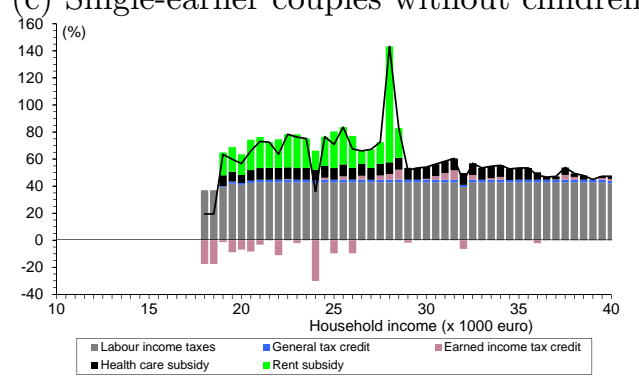

(e) Dual-earner couples without children

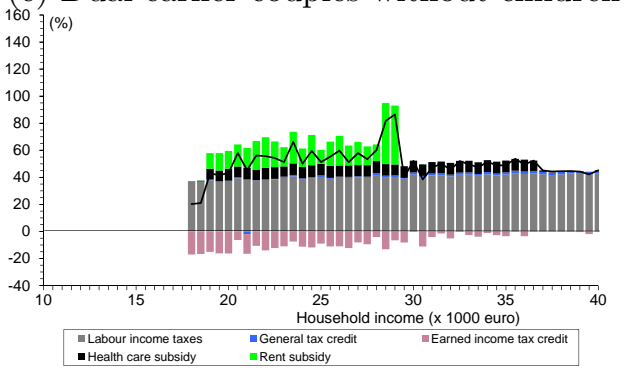

(b) Single parents
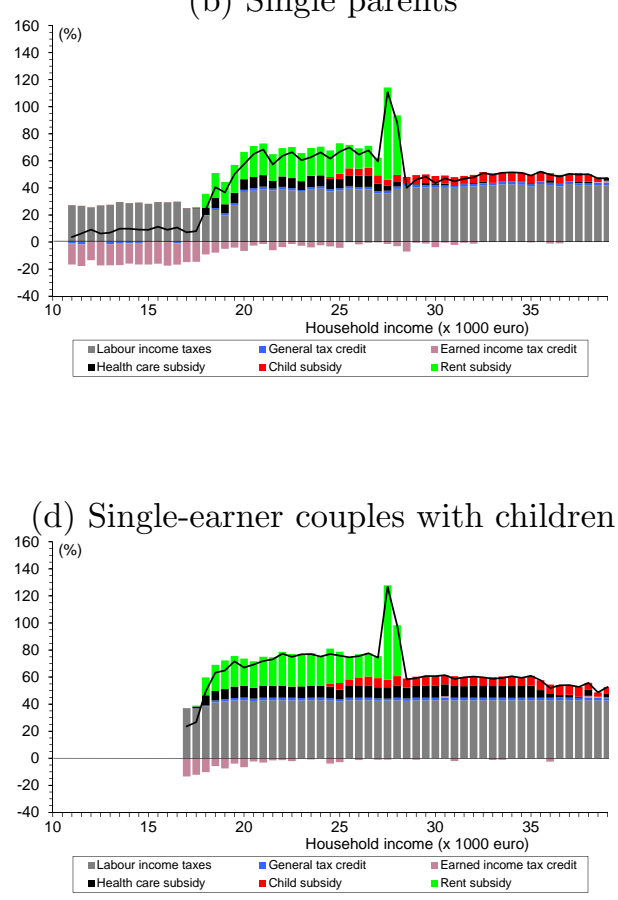

(f) Dual-earner couples with children

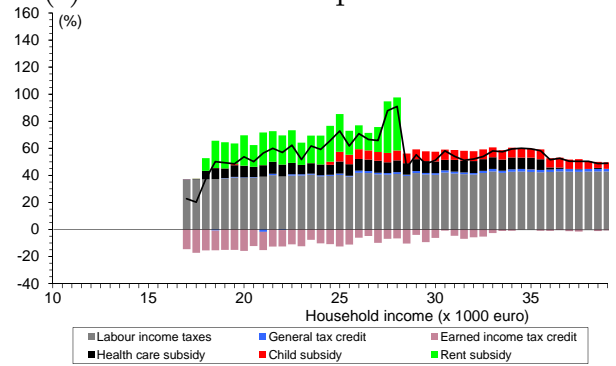

Notes: The figures show the average effective marginal tax rates (solid black lines) and the underlying components for each group by 500 euro bins for the year 2014, using an increase in personal gross income of 3\%. Source: Own calculations using the tax-benefit calculator MIMOSI of CPB. 
euro, and so does the phase out of the general tax credit from 19 thousand euro onwards. The 'baseline' EMTR (the solid black line) before the kink at 15 thousand euro is (approximately) 20 percentage points, after which it jumps to 45 percentage points. Note that the EMTR before the notch around 22 thousand euro is already between 70 and 80 percentage points, as the phase in of the earned income tax credit stops and the individuals jump to a higher tax bracket rate.

EMTRs are initially lower for single parents than for childless singles, because of the phase in of the additional earned income tax credit for single parents and secondary earners in couples with children up to 12 years of age. The kink in the housing benefit raises EMTRs for single parents with incomes above 19 thousand euro by (approximately) 20 percentage points. Before the notch at 29 thousand euro their EMTR is close to 70 percentage points. ${ }^{20}$

For single-earner couples, at the kink of 19 thousand euro for the housing benefit, the EMTR jumps up to 60-65 percentage points. Before the notch, the EMTR is already close to 70 percentage points. The pattern of EMTRs for single-earner couples with children is quite similar, though EMTRs are about 5 percentage points higher due to the phase out of the child benefit. For dual-earner couples without children, the phase out of the housing benefit pushes EMTRs to 60-65 percentage points after the kink, and again the EMTRs for dual-earner couples with children are somewhat larger due to the phase out of the child benefit.

\footnotetext{
${ }^{20}$ After the notch the EMTRs drop to 50 percentage points, somewhat more than for childless singles because of the phase out of the child benefit.
} 


\subsection{Data}

For the empirical analysis we use several administrative data sets from Statistics Netherlands (CBS), covering the years 2007-2014. First, we combine individuals' tax data containing income, wealth and benefit take-up with information on demographic and socioeconomic variables. Second, we aggregate these data on the level of households. ${ }^{21}$ We enrich these data with information on ownership status (owner-occupied or tenant) for the entire Dutch population. These data allow us to obtain the relevant income and wealth concept in terms of the different benefits for all Dutch households.

We make the following selections. In all cases we exclude households in which any of the household members changed their address during the year, such that we only use households that are stable in terms of address and household composition. When looking at the housing benefit, we only include households that rent and select on age, net wealth and social benefits. We only include households whose oldest members are aged between 23 and 65, as different rules apply to those aged below 23 or over 65 and potential income responses in these groups will be strongly muted by students and retirees, respectively. We remove households with net wealth exceeding the wealth threshold and households in owner-occupied houses, since these are not eligible for the housing benefit. Households with any kind of social benefits are removed. In some cases the statutory level of benefits lies just below the kink or notch point so that these benefits create artificial bunching that should not be mistaken for bunching as a consequence of behavioural responses. We do not observe

\footnotetext{
${ }^{21}$ For the housing benefit, the relevant income is the total income earned by everyone living on the same address. When discussing the housing benefit we use the terms "household" and "address" interchangeably. While strictly speaking only the latter is correct, in most cases the two terms overlap and are identical.
} 
the rent, so households that are not eligible for the housing benefit because their rent is too low (in relation to their income) or too high (above the rent threshold) are still included in the analysis, while no bunching is expected for these households.

Among tenants in the lowest quintile (all satisfying the maximum income condition) only $50 \%$ received the housing benefit, reflecting not just ineligibility in the non-income dimension, but also non-take-up among those who are eligible. ${ }^{22}$ Figure 4 shows that $60 \%$ of tenants (who are below the wealth threshold) near the notch do not take up the housing benefit. However, this also includes tenants for which the housing benefit is already phased out at their level of income. As explained in Section 3.1.1, the size of the housing benefit depends on the rent and decreases with income. For this reason, the personal 'costs' of non-take-up are lower the closer households get to the income threshold. A second potential reason for a low take-up close to the notch is the increased risk of having to pay back the advance, when the realised annual income ends up above the threshold. For the 2015 fiscal year, about 400.000 households had to pay back an average of 723 euro (Berkhout and Bosch, 2018).

\footnotetext{
${ }^{22}$ See Tempelman et al. (2011) and Tempelman and Houkes-Hommes (2016) for an analysis of non-take-up behaviour in the Netherlands. For the housing benefit, they estimate a non-take-up percentage of $18 \%$ among those eligible.
} 
Figure 4: Take-up rate housing benefits by household type in 2014

(a) Childless singles

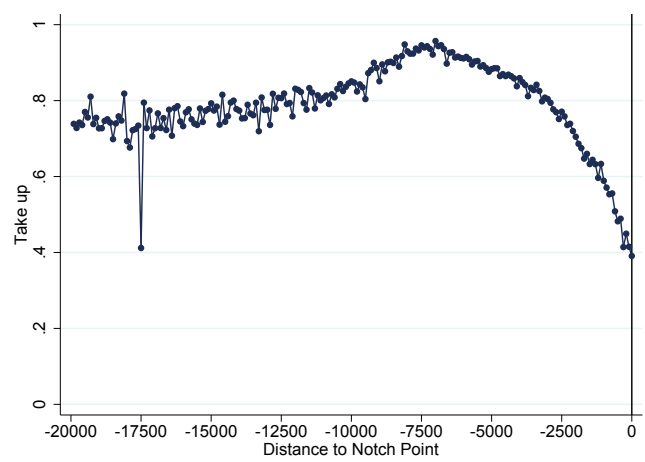

(c) Couples w/o children

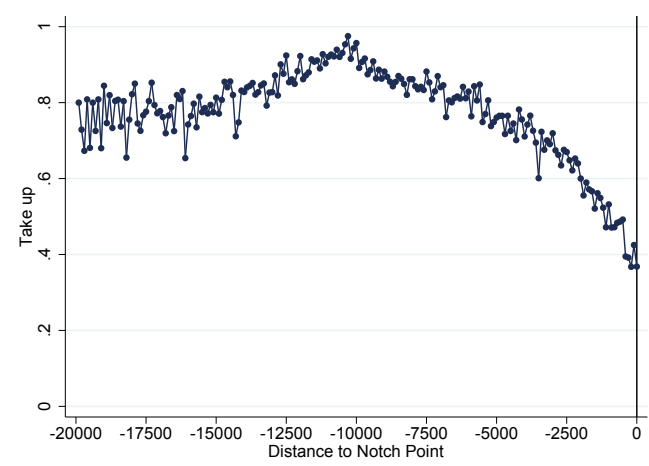

(b) Single parents

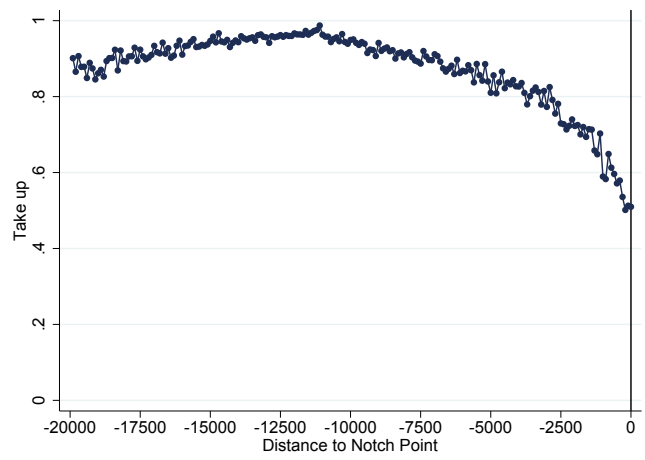

(d) Couples with children

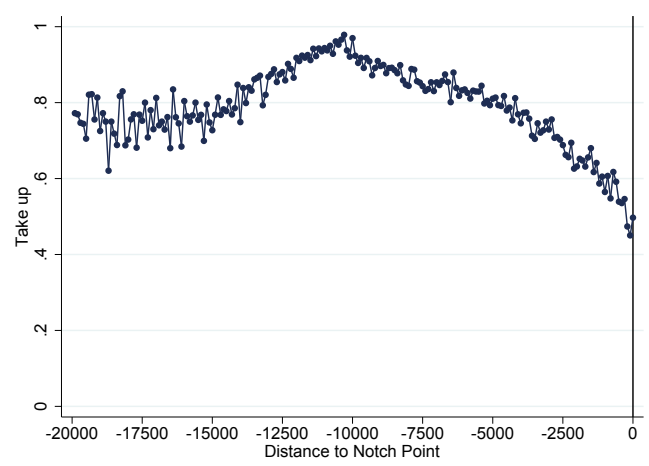

When looking at the wealth notch created by the health care and child benefit, we select on age and income. We remove households where the oldest member is younger than 18 and households with an income above the health care threshold, as these are not eligible for the health care benefit. We classify households in several groups. We consider singles and couples, both with and without children. Furthermore, we separate employees and self-employed, using data on the main source of income of the highest earning household member. 


\section{Results}

\subsection{Income}

First, we consider graphical evidence of bunching around the kink and notch of the housing benefit. In Figures 5 and 6 we show the true and counterfactual densities around the taxable income kinks and notches of the housing benefit.

In Figure 5 we consider four household types: childless singles, single parents, couples without children, and couples with children. Recall that we distinguish between these four household types as they differ in the location of the kink and/or notch in terms of income. There is no sign of statistically significant bunching for any household type, either at the kink or at the notch, with the exception of the kink for couples with children, which shows small but positive bunching. ${ }^{23}$ Previous studies have typically found very little bunching by employees, but substantial bunching by self-employed because the self-employed can adjust their income more easily (Kleven, 2016). In Figure 6 we present results separately for the self-employed. However, again, we see no bunching at either the kink or notch point, with the exception of the notch for childless singles, which (mysteriously) produces a negative estimate of the amount of bunching. This is in contrast to the bunching of the self-employed at the tax bracket threshold going from the 3rd to the 4th bracket, see Figure A.10, panels $\mathrm{b}$ and $\mathrm{d}$, in the supplementary material. Interestingly, the self-employed do not seem to bunch (much) at the first tax bracket threshold, which is closer to the housing benefit notch point, see Figure A.10, panels a and c in the supplementary material. This suggests that the high earning self-employed may be quite different than the low-earning self-employed in terms of their ability to manipulate income.

\footnotetext{
${ }^{23}$ The same is true for each individual year, see the supplementary material.
} 
Figure 5: Bunching at kinks and notches housing benefits: by household type

(a) Childless singles kink

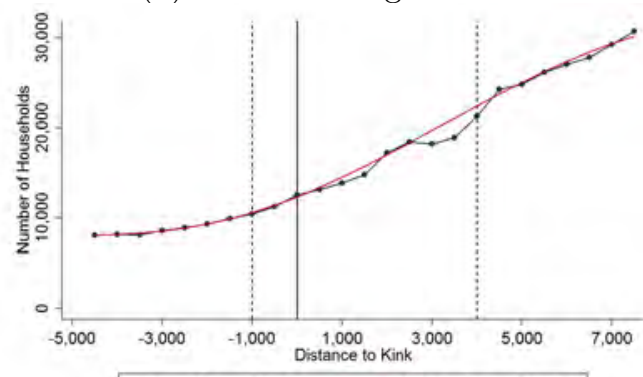

$\longrightarrow$ Actual Density Counterfactual Density

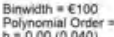

(c) Single parents kink

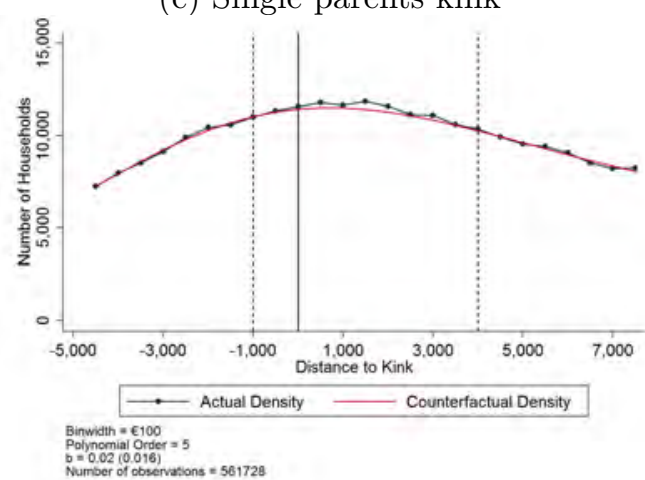

(e) Couples w/o children kink

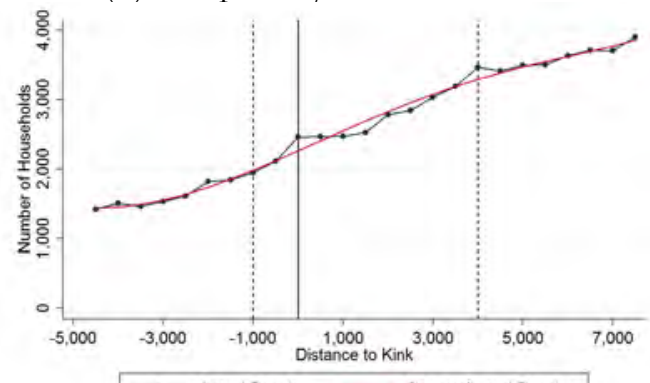

$\longrightarrow$ Actual Density Counterfactual Density

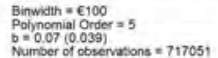

(g) Couples with children kink

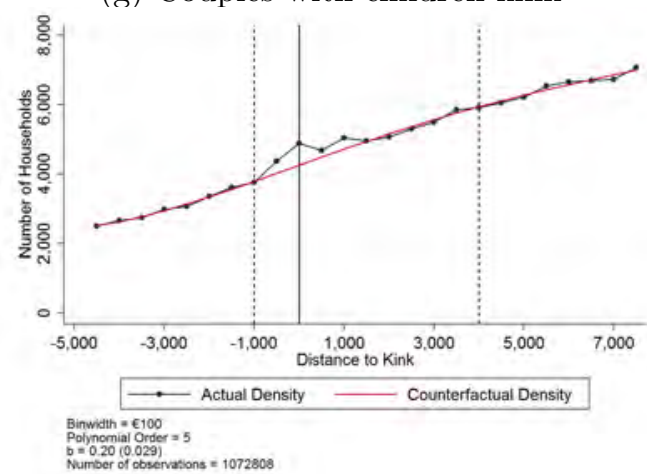

(b) Childless singles notch

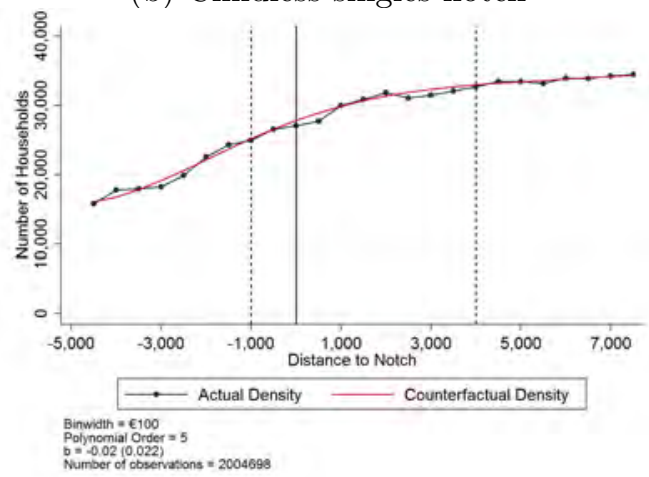

(d) Single parents notch

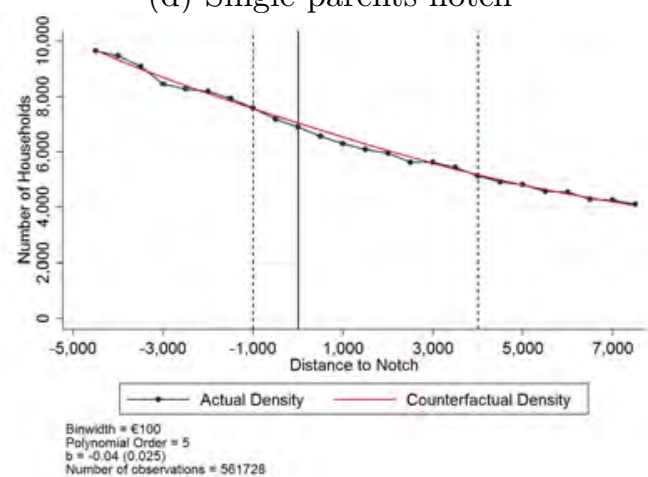

(f) Couples w/o children notch

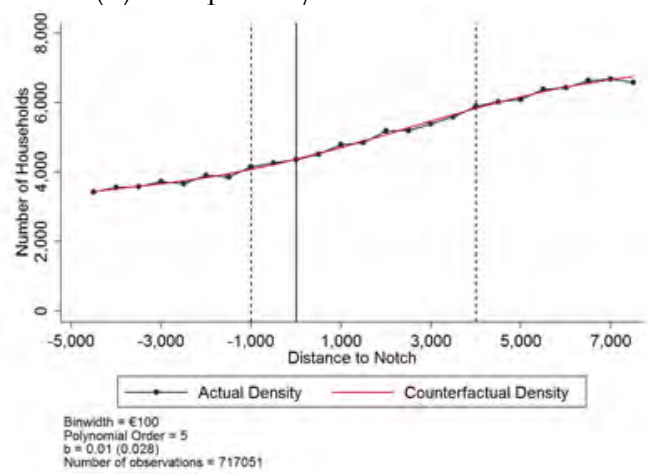

(h) Couples with children notch

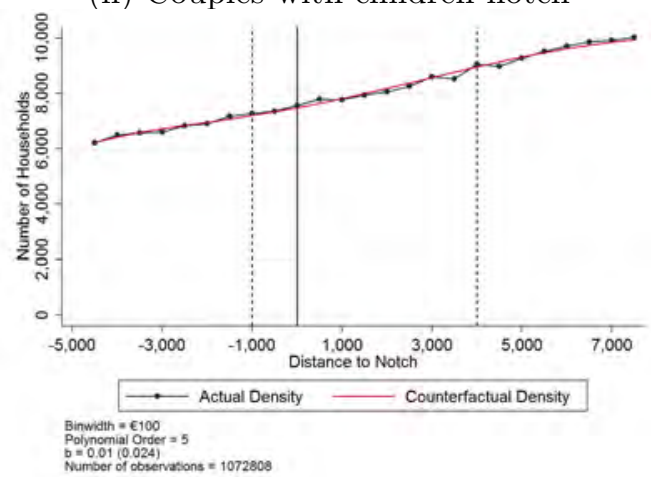


Figure 6: Bunching at kinks and notches housing benefits: self-employed

(a) Childless singles kink

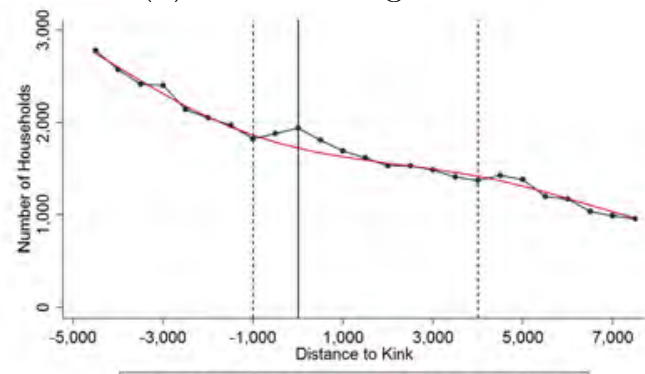

$\longrightarrow$ Actual Density $\longrightarrow$ Counterfactual Density

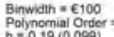

(c) Single parents kink

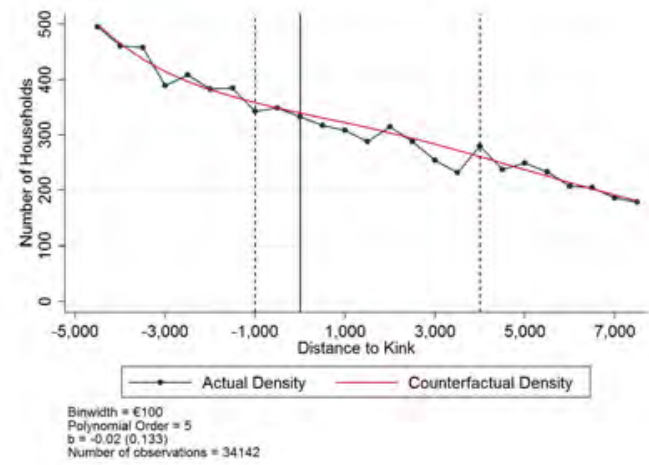

(e) Couples w/o children kink

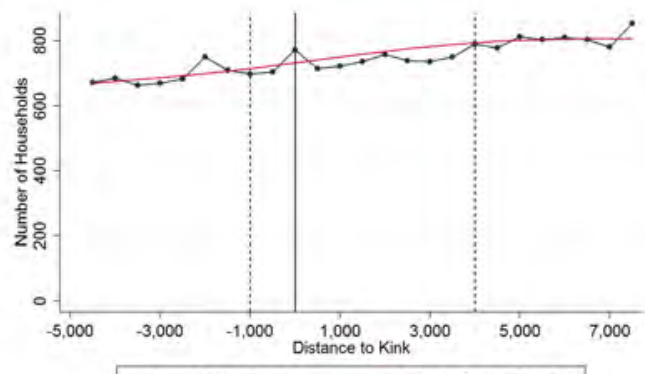

$\longrightarrow$ Actual Density $\longrightarrow$ Counterfactual Density

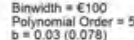

(g) Couples with children kink

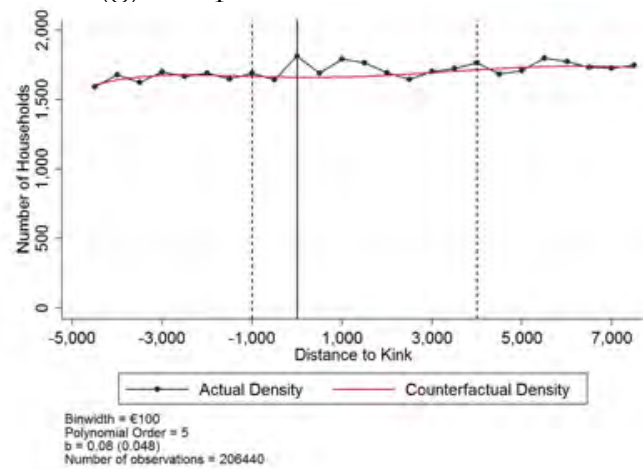

(b) Childless singles notch

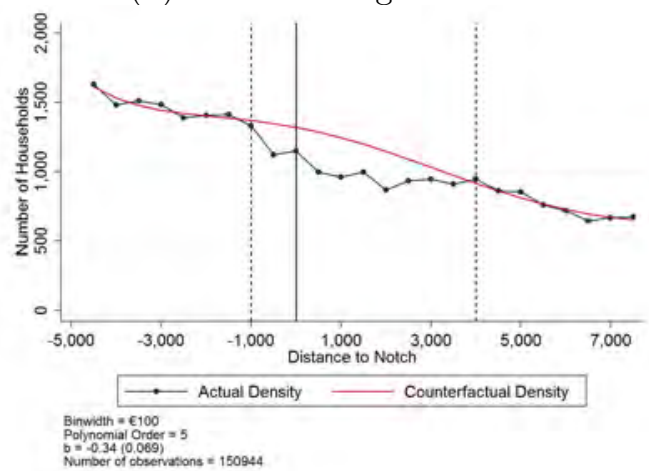

(d) Single parents notch

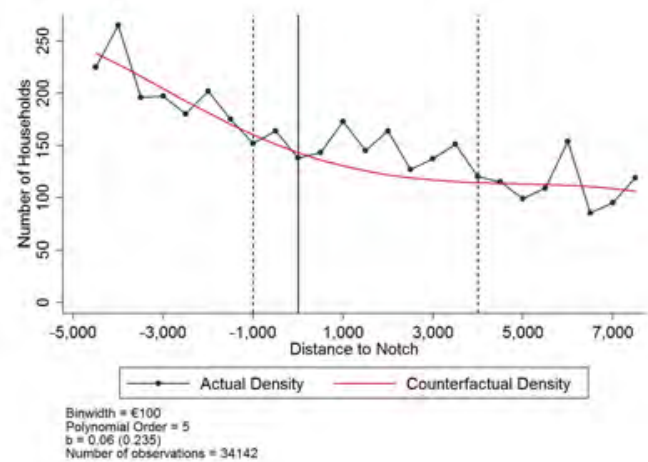

(f) Couples w/o children notch

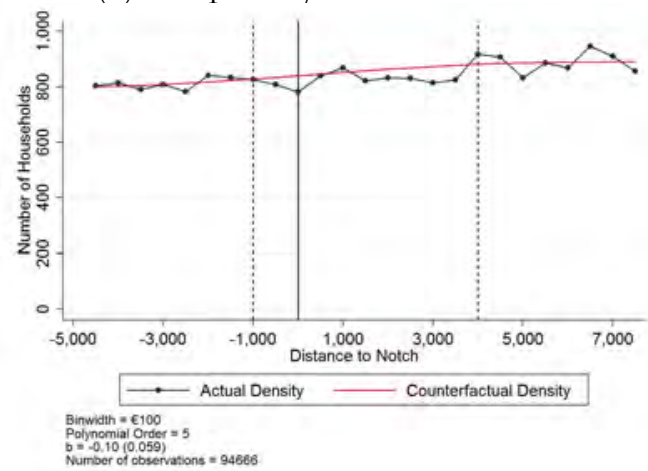

(h) Couples with children notch

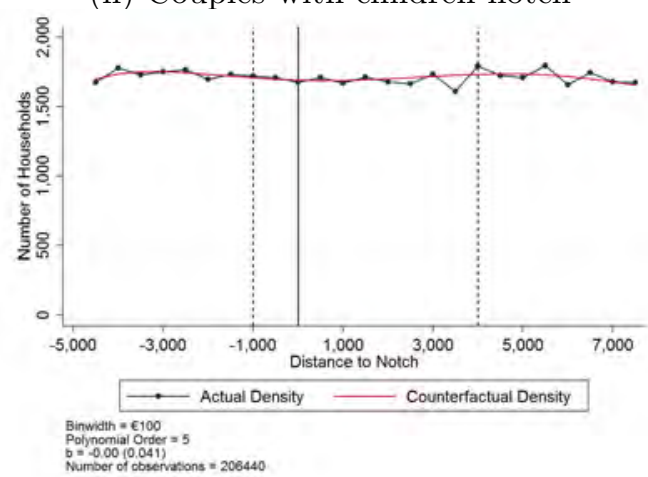


Table 1: Survival rates in different income brackets: by income bracket in 2011

\begin{tabular}{cccccc}
\hline \hline Year & {$[-3000,-1500]$} & {$[-1500,0]$} & {$[0,1500]$} & {$[1500,3000]$} & {$[3000,4500]$} \\
\hline 2007 & $7 \%$ & $7 \%$ & $7 \%$ & $7 \%$ & $6 \%$ \\
2008 & $10 \%$ & $10 \%$ & $10 \%$ & $10 \%$ & $10 \%$ \\
2009 & $19 \%$ & $19 \%$ & $19 \%$ & $19 \%$ & $17 \%$ \\
2010 & $27 \%$ & $27 \%$ & $27 \%$ & $26 \%$ & $24 \%$ \\
2011 & $100 \%$ & $100 \%$ & $100 \%$ & $100 \%$ & $100 \%$ \\
2012 & $25 \%$ & $26 \%$ & $25 \%$ & $24 \%$ & $23 \%$ \\
2013 & $19 \%$ & $19 \%$ & $18 \%$ & $16 \%$ & $15 \%$ \\
2014 & $13 \%$ & $12 \%$ & $11 \%$ & $10 \%$ & $10 \%$ \\
\hline \hline
\end{tabular}

Since we have panel data on households, we can also study the dynamics around the kink and the notch. Table 1 shows the survival rates of households in income intervals around the notch. The table displays the share of individuals who are in the same income bracket as in 2011. Individuals with an income between 0 and 1500 euro above the income threshold are in the dominated region. Among individuals in the dominated region in 2011, $27 \%$ were in the same income bracket the year before and $25 \%$ are still in this income bracket one year later. Moreover, across the income cells there is no observable difference in income volatility for those in the dominated region $(0-1,500$ euro) and other income brackets. Individuals in the dominated region do not seem to change their income more than individuals who started with lower or higher incomes in 2011. This is an indication that income fluctuations are to a large extent unrelated to the notch. There is, however, substantial income volatility around the notch, such that households typically do not stay in the dominated region for many years. After one year the majority (75\%) earns a higher or lower income and after three years only $11 \%$ are still in the dominated region. This income volatility might also make households reluctant to apply for the housing benefit for 
fear of having to pay it back. Indeed, we see substantial non-take-up of the housing benefit, where the non-take-up is higher close to the notch (see Figure 4). For the kink we also find substantial income dynamics, which are similar to the 'left' and 'right' of the kink (available on request).

\subsection{Wealth}

As described in Section 3, eligibility for housing benefits, health care benefits and child benefits is conditional on net wealth being below a certain threshold. When net wealth is above this threshold, eligibility for the benefits is suddenly removed, causing significant notches. Households that are otherwise eligible for any of these benefits therefore have an incentive to keep their wealth just below the threshold rather than just above the threshold. This can be done, for example, by increasing their spending on consumption or by giving away wealth, or by converting assets into assets that are not included in the definition of net wealth (like durable goods or pension assets). Homeowners with mortgage debt can also reduce their net wealth by improving their home or by making repayments on their mortgage, as the primary home and fiscally associated mortgage debt are both excluded from the net wealth definition. Finally, households can also evade tax by hiding and not declaring cash or other financial assets that are not being registered. For households that are in the dominated region (with an excess wealth above the threshold that is lower than the benefit they lose), spending this excess wealth is essentially equivalent to buying products for a negative price. Therefore we expect bunching just before the threshold of net wealth.

In this analysis, we cannot study the wealth thresholds that apply to the housing 
benefit. The reason for this is that fiscal data on net wealth are not available for households below this threshold. The threshold for the health care and child benefit is higher and fiscal data is available for households below and above the threshold. Moreover, this threshold was introduced in 2013, which allows us to compare the net wealth distribution before and after this policy change. This policy change in 2013 was made public in September 2012 and the level of net wealth is evaluated on the 1st of January. We therefore expect no bunching before the threshold in 2011 or 2012 and bunching in 2013 and later years.

Figure 7 shows the net wealth distribution of singles with and without children around the threshold and Figure 8 shows this for couples with and without children. The graphs show the distribution of net wealth two years before the policy change (2011 and 2012) and two years after the policy change (2013 and 2014). ${ }^{24}$ We do not observe any bunching in either the pre-reform years (2011 and 2012) or the post-reform years (2013 and 2014), with the exception of couples without children in 2013. Interestingly while there is no evidence of excess mass (bunching), there appears to be missing mass to the right of the notch for childless singles in 2013, the year when the notch was first introduced. Google searches do indeed suggest that interest in these benefits' wealth condition surged just ahead of its implementation (see Figure A.14).

We have also looked at the dynamics of wealth around the notch of health care benefits in a similar way as for income around the notch of housing benefits (details available on request). We only looked at households with an income below the income threshold in 2013. We considered the households with a taxable wealth

\footnotetext{
${ }^{24}$ For 2011 and 2012 we downrate the wealth threshold from 2013 to 2011 and 2012 respectively, using the CPI.
} 
Figure 7: Bunching at wealth notch singles with and w/o children

(a) Childless singles 2011

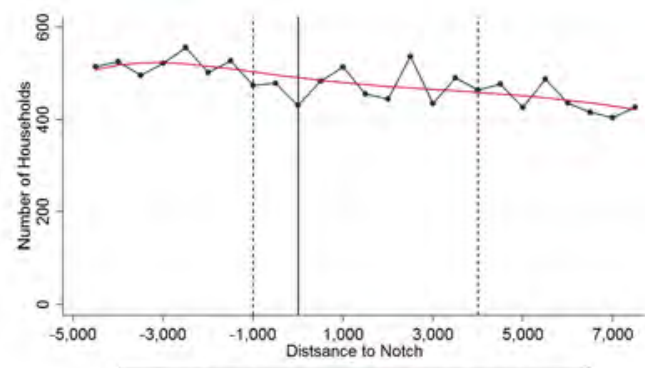

- Actual Density $\longrightarrow$ Counterfactual Density

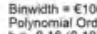

(c) Childless singles 2013

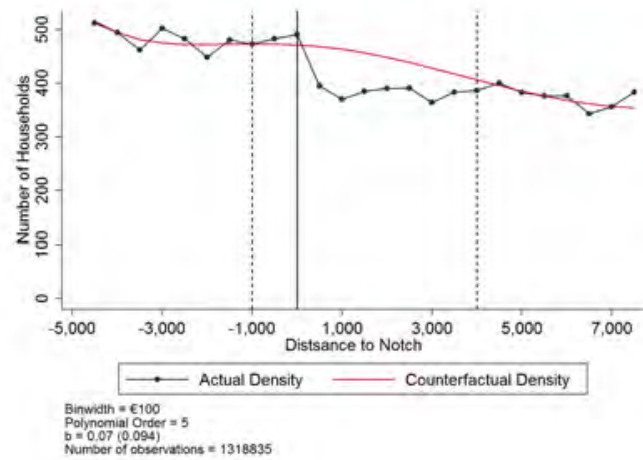

(e) Single parents 2011

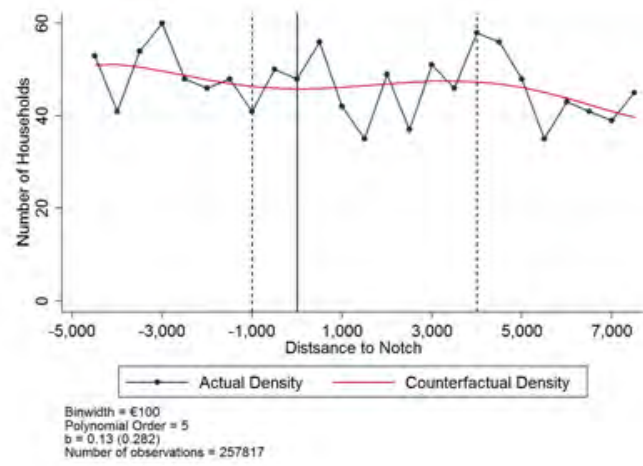

(g) Single parents 2013

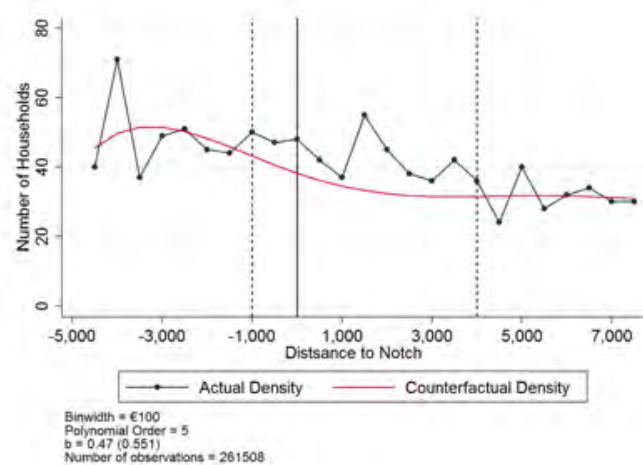

(b) Childless singles 2012

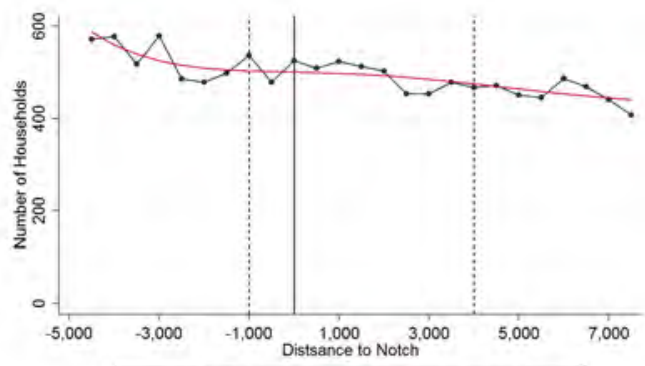

Binwath = $\epsilon 100$
Polynomial Orde

(d) Childless singles 2014

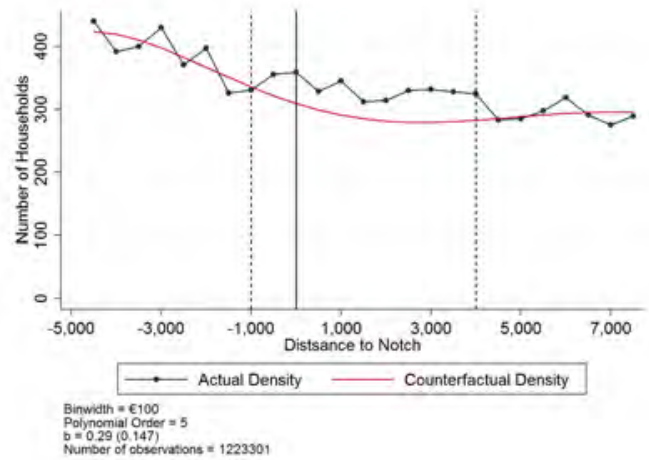

(f) Single parents 2012

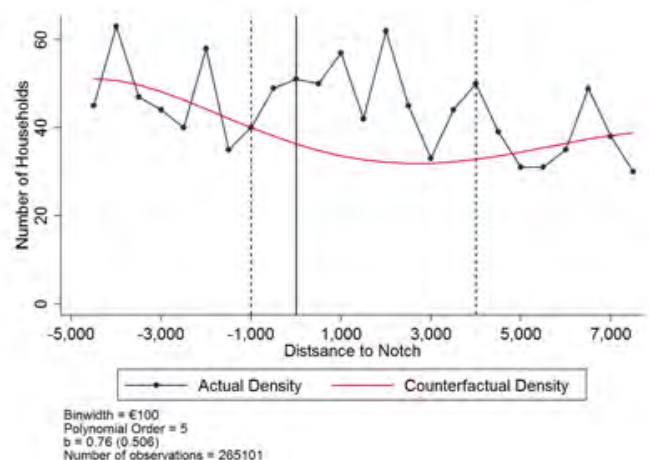

(h) Single parents 2014

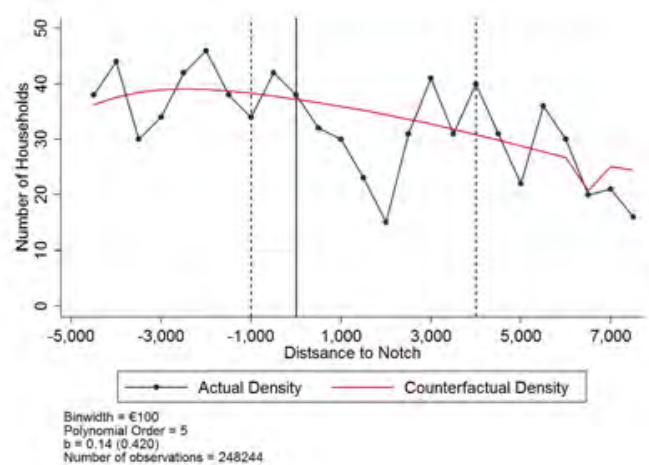


Figure 8: Bunching at wealth notch couples with and w/o children

(a) Couples w/o children 2011

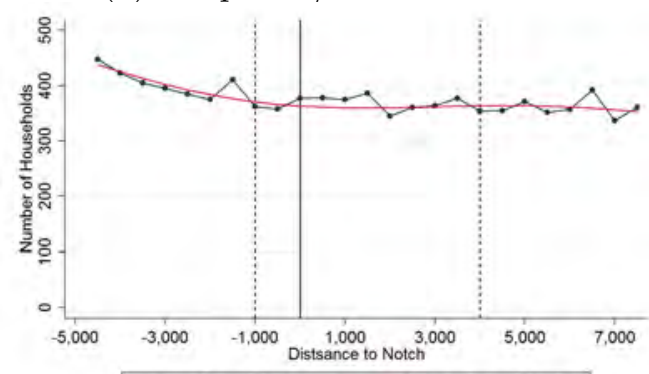

- Actual Density $\quad$ Counterfactual Density

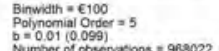

(c) Couples w/o children 2013

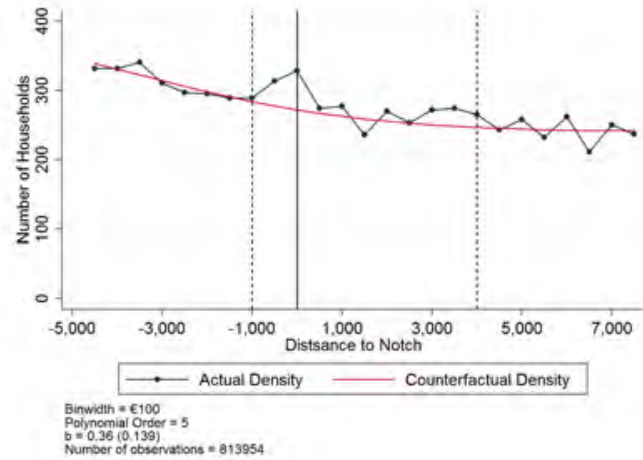

(e) Couples with children 2011

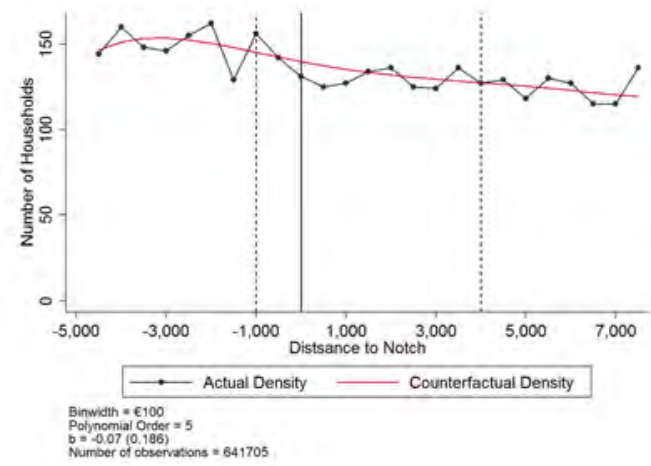

(g) Couples with children 2013

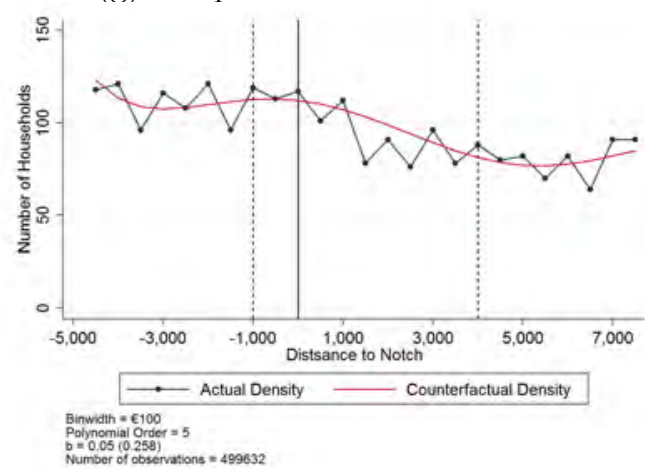

(b) Couples w/o children 2012

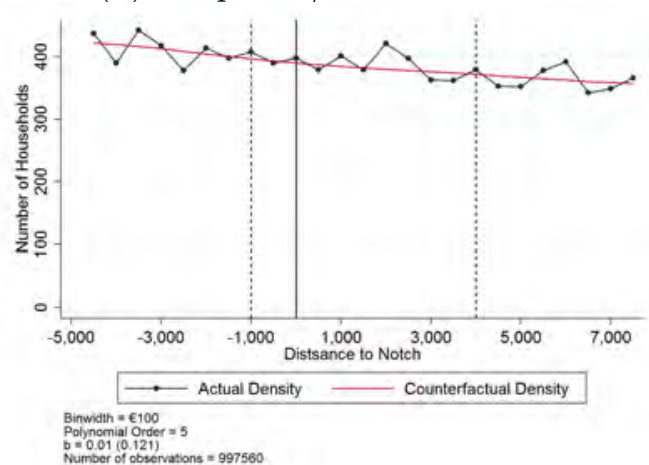

(d) Couples w/o children 2014

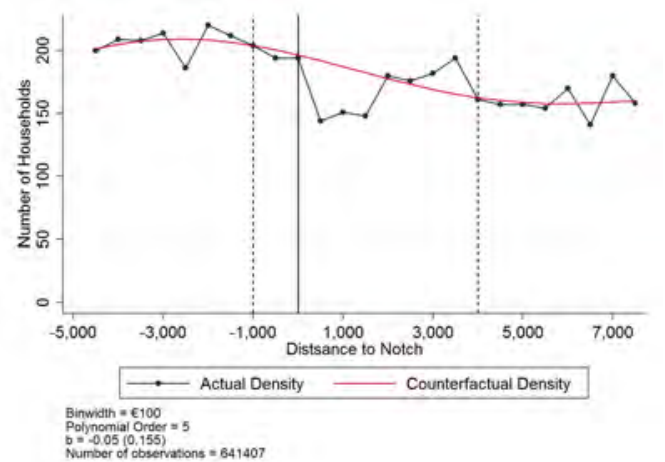

(f) Couples with children 2012

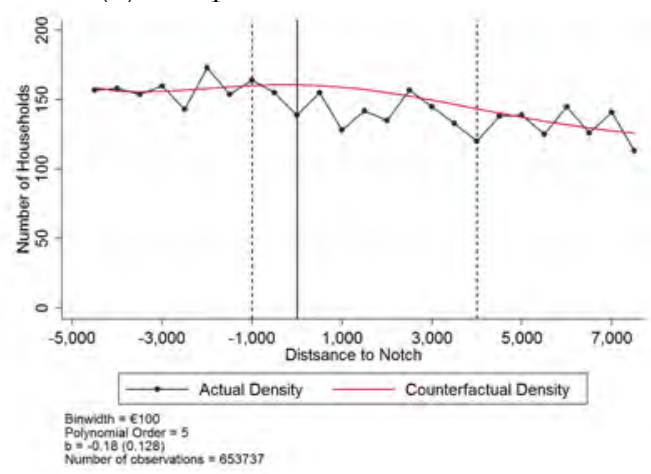

(h) Couples with children 2014

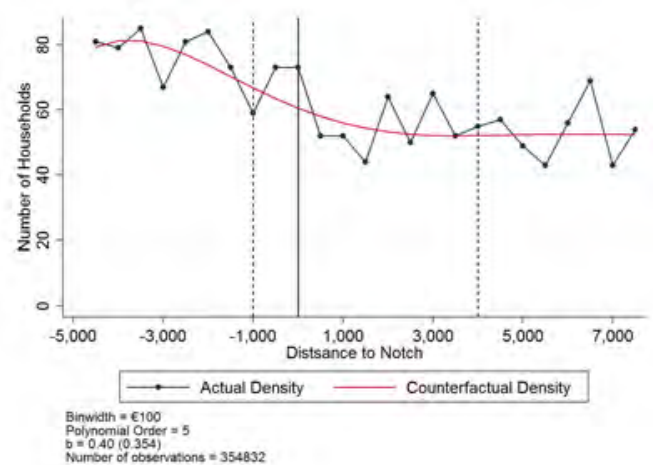


within 10,000 euro of the notch in 2013 and traced these in the years before and after 2013. In the years before 2013 we used a fictional wealth threshold by deflating the threshold of 2013, since eligibility for health care benefits did not yet depend on wealth before 2013. We considered four brackets of 5,000 euro around the threshold. Just as for income, we find strong dynamics with respect to the distance to the threshold and households generally do not stay in the same wealth bracket for long. As with the income notch, this pattern does not appear to be different for the brackets to the left and to the right of the threshold.

\section{Discussion}

We find essentially no evidence of bunching at kinks or notches, neither in taxbale income nor in taxable wealth. What are the potential mechanisms that can explain this non-bunching?

A low elasticity of income with respect to marginal tax rates is unlikely to explain the non-bunching. Indeed, even for a low elasticity in the order of $[0.01,0.1]$, we would expect substantial bunching in the absence of frictions (Bastani and Selin, 2014). ${ }^{25}$

An alternative explanation would be that the financial incentives are simply not strong enough. The substantial non-take-up of the housing benefit implies that the kink and the notch is not relevant for all tenants. However, as we have shown in the section on the institutional context and data, even after accounting for non-take-up, we see a large kink due to the phase out of the housing benefit. Furthermore, for

\footnotetext{
${ }^{25}$ Using the Gruber-Saez methodology, Jongen and Stoel (2016) estimate an elasticity of taxable income of 0.12 (using a 5-piece spline in base year income to control for e.g. mean revision) to 0.22 (using log base year income to control for e.g. mean revision) for the income range 10 to 50 thousand euro, using data from the period 1999-2005.
} 
the majority of household types there is still a substantial notch for the group of tenants as a whole (where the notch, and hence the financial incentive, is much larger for tenants that do take up the housing benefit). However, it is important to note that there are substiantial income and wealth dynamics around the kink and notch, which limits the time period people individals spend in dominated regions and in regions with very high marginal tax rates. Still, in the absence of frictions, we would expect to observe bunching, when individuals can freely choose their income in a given year.

Hence, frictions likely play an important role in driving our results. One type of friction that may limit the extent of bunching are adjustment costs, which prevent households from choosing their income e.g. outside the dominated region of the notch. Unfortunately we cannot test the importance of adjustment costs in our analysis directly, because we do not have substantial shifts in the location of the kink and notch. Adjustment costs may very well play a role in the results we find, however this is unlikely to be the sole explanation for the non-bunching we observe. A number of observations are inconsistent with a large role for adjustment costs. First, we do not observe bunching before the kinks and notches of the housing benefit for the self-employed. Self-employed are arguably more able to manipulate their taxable income, as evidenced by the bunching of taxable income of self-employed around tax bracket thresholds. Second, we do not observe bunching before the notch in the wealth-dependent benefit for children and health care. Taxable wealth can be reduced easily by increasing consumption or by buying durable goods before the end of the fiscal year. Also, if adjustment costs are the only mechanism at work to prevent sharp bunching, we would still expect 'fuzzy' bunching around the kink and the notch (Søgaard, 2019), but we find essentially no statistically significant 
bunching.

We argue that a lack of salience and inattention play an important role in the non-bunching we observe. The income- and wealth-dependent benefits we study are quite complex and it is doubtful that tenants are actually aware of the precise implicit increase in their marginal tax rate, so that bunching may be seriously attenuated by a lack of salience. ${ }^{26}$ This can also explain why we observe bunching for self-employed for the tax bracket thresholds, but not for the housing benefit threshold. Furthermore, we also do not observe gradual learning, as income and wealth dynamics around the notch are not different for income and wealth intervals just below and just above the notch, which also suggests that households are largely unaware of the threshold. This is also consistent with a lack of salience and inattention.

\section{Conclusion}

In this paper we have shown that kinks and notches in the system of targeted cash tranfers generally do not cause significant bunching in taxable income or taxable wealth in the Netherlands, using an administrative dataset for the universe of Dutch households for the period 2007-2014. We argue that the lack of bunching cannot be explained by a low structural elasticity of taxable income or weak financial incentives. Indeed, frictions such as adjustment costs and a lack of salience or inattention to how targeted cash transfers depend on taxable household income and wealth likely

\footnotetext{
${ }^{26}$ Chetty et al. (2013) demonstrate the importance of households understanding of the EITC in determining their labour supply. Feldman et al. (2016) show how households' behaviour is at least partly driven by confused beliefs about the EITC. It is not too far a stretch to think that lack of knowledge and confusion play a role in labour supply around the kink and notch of the Dutch housing benefit.
} 
play an important role. Because we do not observe bunching among self-employed or for wealth, where adjustment costs are less important, we argue that the results are more likely to be due to a lack of salience and inattention. If adjustment costs were the sole explanation, we would expect to see fuzzy bunching (which we do not). Furthermore, we also do not find evidence of gradual learning, which is consistent with a lack of salience and inattention.

Given the small behavioural responses, the efficiency losses from targeted cash tranfers seem limited. However, the downside is that there is a substantial group in the target population that does not take up the benefits to which they are entitled. Furthermore, large kinks and notches are inconsistent with a well-behaved social welfare function, because income support then differs substantially between households that differ only marginally in income. In this light, current plans to replace the income threshold for the housing benefit by a more gradual phase out in the future seem appropriate.

A number of interesting avenues for future research remain. Reliable data on wealth below the taxable wealth threshold would allow for an analysis of bunching of taxable wealth at the notch of the housing benefit, a more dense area in the wealth distribution than that for the health care and child benefit. An analysis of extensive margin responses to cash tranfers also seems an interesting direction for future research. 


\section{References}

Adam, Stuart, James Browne, David Phillips, and Barra Roantree, "Frictions and Taxpayer Responses: Evidence from Bunching at Personal Tax Thresholds," mimeo, IFS, London August 2017.

Attanasio, Orazio, "Consumer Durables and Inertial Behaviour: Estimation and Aggregation of (S,s) Rules for Automobile Purchases," Review of Economic Studies, 2000, 67 (4), 667-696.

Bastani, Spencer and Håkan Selin, "Bunching and Non-Bunching at Kink Points of the Swedish Tax Schedule," Journal of Public Economics, 2014, 109, $36-49$.

Berkhout, Ernest and Nicole Bosch, "Hoger Inkomen Voornaamste Oorzaak Terugbetalen Huurtoeslag," ESB December 2018.

Best, Michael Carlos and Henrik Jacobsen Kleven, "Housing Market Responses to Transaction Taxes: Evidence From Notches and Stimulus in the U.K.," Review of Economic Studies, 2018, 85 (1), 157-193.

Bettendorf, Leon J.H., Arjan M. Lejour, and Maarten van 't Riet, "Tax Bunching by Owners of Small Corporations," Discussion Paper 326, CPB Netherlands Bureau for Economic Policy Analysis March 2016.

Brülhart, Marius, Jonathan Gruber, Matthias Krapf, and Kurt Schmidheiny, "Taxing Wealth: Evidence from Switzerland," Working Paper 22376, National Bureau of Economic Research June 2016. 
Chetty, Raj, "Bounds on Elasticities with Optimization Frictions: A Synthesis of Micro and Macro Evidence on Labor Supply," Econometrica, 2012, 80 (3), 969-1018.

_, John N. Friedman, and Emmanuel Saez, "Using Differences in Knowledge across Neighborhoods to Uncover the Impacts of the EITC on Earnings," American Economic Review, December 2013, 103 (7), 2683-2721.

_, _, Tore Olsen, and Luigi Pistaferri, "Adjustment Costs, Firm Responses, and Micro vs. Macro Labor Supply Elasticities: Evidence from Danish Tax Records," The Quarterly Journal of Economics, 2011, 126 (2), 749-804.

Commissie Inkomstenbelasting en Toeslagen, Naar een Activerender Belastingstelsel. Eindrapport, Ministerie van Financien, 2013.

CPB, "Gebruik Aftrekpost Scholingsuitgaven per Inkomensgroep," CPB Notitie November 3 The Hague 2016.

Dekker, Vincent, Kristina Strohmaier, and Nicole Bosch, "A Data-Driven Procedure to Determine the Bunching Window: An Application to the Netherlands," Discussion Paper 336, CPB Netherlands Bureau for Economic Policy Analysis September 2016.

Feldman, Naomi E., Peter Katuščák, and Laura Kawano, "Taxpayer Confusion: Evidence from the Child Tax Credit," American Economic Review, March 2016, $106(3), 807-35$.

Gabaix, Xavier, "Behavioral Inattention," Working Paper 24096, National Bureau of Economic Research December 2017. 
Gelber, Alexander, Damon Jones, and Daniel W. Sacks, "Estimating Earnings Adjustment Frictions: Method and Evidence from the Social Security Earnings Test," Working Paper, UC Berkeley Goldman School of Public Policy March 2017.

Gruber, Jon and Emmanuel Saez, "The Elasticity of Taxable Income: Evidence and implications," Journal of Public Economics, 2002, 84 (1), 1 - 32.

Hargaden, Enda Patrick, "Taxpayer Responses over the Cycle: Evidence from Irish Notches," Working Paper, University of Michigan November 2015.

Jacobs, Bas, Egbert L.W. Jongen, and Floris T. Zoutman, "Revealed Social Preferences of Dutch Political Parties," Journal of Public Economics, 2017, 156, $81-100$.

Jakobsen, Katrine, Kristian Jakobsen, Henrik Kleven, and Gabriel Zucman, "Wealth Taxation and Wealth Accumulation: Theory and Evidence from Denmark," Working Paper 24371, National Bureau of Economic Research March 2018.

Jones, Damon and Ioana Marinescu, "The Labor Market Impacts of Universal and Permanent Cash Transfers: Evidence from the Alaska Permanent Fund," Working Paper 24312, National Bureau of Economic Research February 2018.

Jongen, Egbert L.W. and Maaike Stoel, "The Elasticity of Taxable Labour Income in the Netherlands," Discussion Paper 337, CPB Netherlands Bureau for Economic Policy Analysis October 2016. 
Kleven, Henrik Jacobsen, "Bunching," Annual Review of Economics, 2016, 8, $435-464$.

_ and Esben Anton Schultz, "Estimating Taxable Income Responses Using Danish Tax Reforms," American Economic Journal: Economic Policy, November 2014, $6(4), 271-301$.

_ and Mazhar Waseem, "Using Notches to Uncover Optimization Frictions and Structural Elasticities: Theory and Evidence from Pakistan," The Quarterly Journal of Economics, 2013, 128 (2), 669-723.

_, Martin B. Knudsen, Claus Thustrup Kreiner, Søren Pedersen, and Emmanuel Saez, "Unwilling or Unable to Cheat? Evidence from a Tax Audit Experiment in Denmark," Econometrica, 2011, 79 (3), 651-692.

Koot, Patrick, Marente Vlekke, Ernest Berkhout, and Rob Euwals, "MIMOSI: Microsimulatiemodel voor Belastingen, Sociale Zekerheid, Loonkosten en Koopkracht," CPB Background Document The Hague 2016.

Maire, Daniel Le and Bertel Schjerning, "Tax Bunching, Income Shifting and Self-Employment," Journal of Public Economics, 2013, 10\%, 1 - 18.

Matikka, Tuomas and Tuomas Kosonen, "Discrete Earnings and Optimization Errors: Evidence from Student's Responses to Local Tax incentives," VATT Working Paper 326 Helsinki 2019.

Mirrlees, James A., "An Exploration in the Theory of Optimum Income Taxation," Review of Economic Studies, 1971, 38 (2), 175-208. 
Saez, Emmanuel, "Do Taxpayers Bunch at Kink Points?," Working Paper 7366, National Bureau of Economic Research September 1999.

_ , "Do Taxpayers Bunch at Kink Points?," American Economic Journal: Economic Policy, 2010, 2 (3), 180-212.

_, Joel Slemrod, and Seth H. Giertz, "The Elasticity of Taxable Income with Respect to Marginal Tax Rates: A Critical Review," Journal of Economic Literature, 2012, 50 (1), 3-50.

Seim, David, "Behavioral Responses to Wealth Taxes: Evidence from Sweden," American Economic Journal: Economic Policy, November 2017, 9 (4), 395-421.

Sims, Christopher A., "Implications of Rational Inattention," Journal of Monetary Economics, 2003, 50 (3), 665-690.

Søgaard, Jakob Egholt, "Labor Supply and Optimization Frictions: Evidence from the Danish Student Labor Market," CEBI Working Paper 01/19 Copenhagen 2019.

Statistics Netherlands, Welvaart in Nederland 2016, Centraal Bureau voor de Statistiek, 2016.

Tempelman, Caren, Aenneli Houkes, and Jurriaan Prins, Niet-Gebruik Inkomensondersteunende Maatregelen, SEO Economisch Onderzoek, 2011.

_ and Aenneli Houkes-Hommes, "What Stops Dutch Households from Taking Up Much Needed Benefits?," Review of Income and Wealth, 2016, 62 (4), 685-705.

Zoutman, Floris, "The Effect of Capital Taxation on Household Savings," Working Paper August 2015. 


\section{Supplementary material}

Figure A.1: Notch size as a function of rent

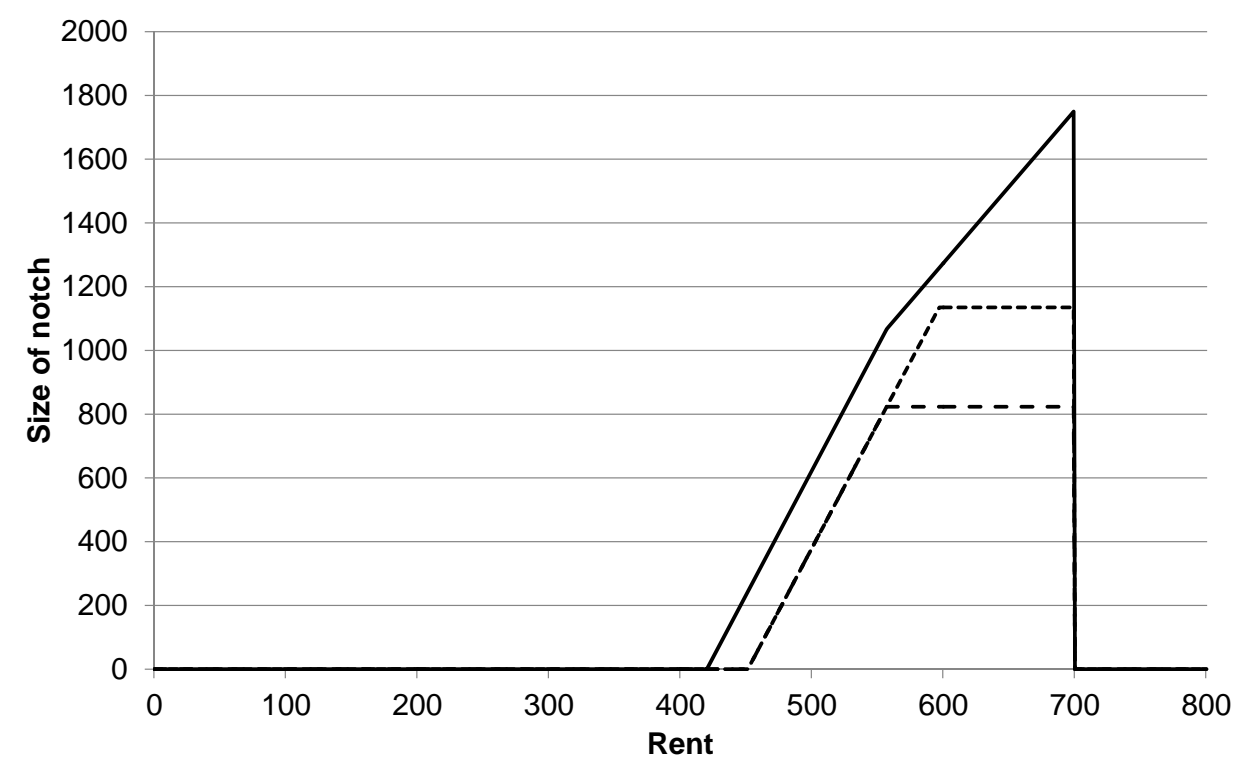

-One person - - Two persons --- Three or more persons

Notes: This graph shows the size of the notch in 2014 for different household types as a function of the monthly rent. 
Figure A.2: Income distribution childless singles around kink: by single year

(a) 2007

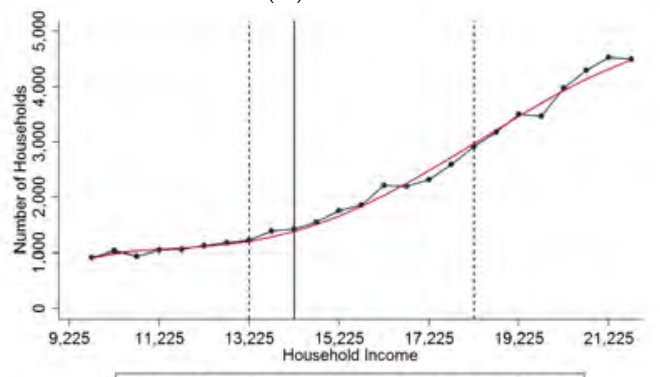

$\longrightarrow$ Actual Density $\longrightarrow$ Counterfactual Density

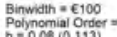

$b=0.08(0,113)$
Number of obsenations $=255883$

(c) 2009

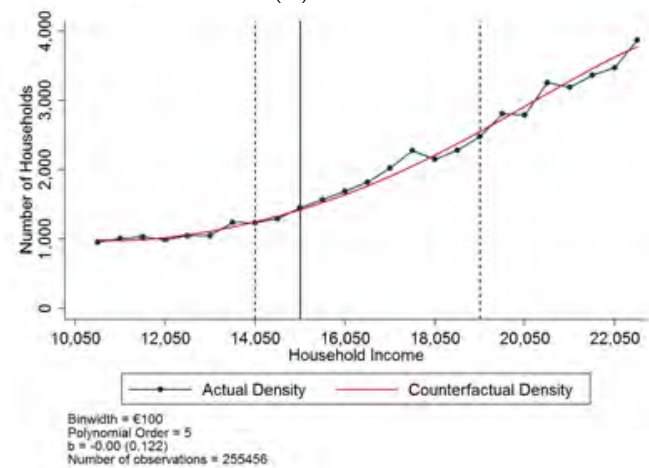

(e) 2011

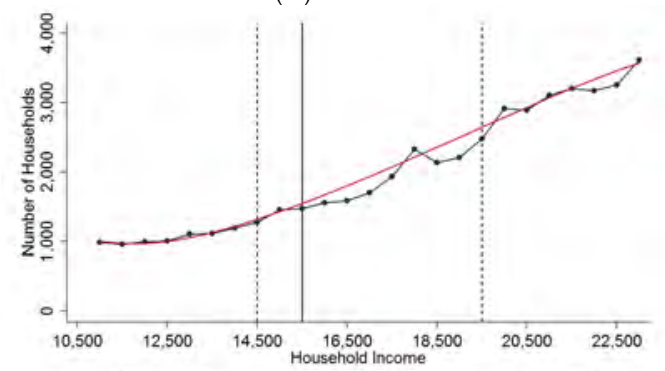

$\longrightarrow$ Actual Density C Counterfactual Density

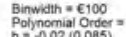

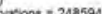

(g) 2013

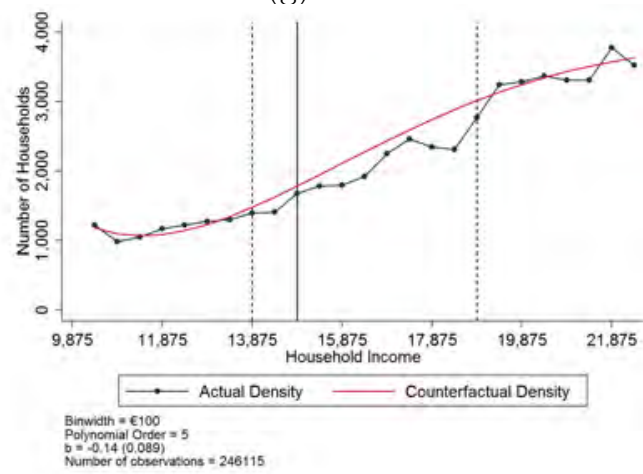

(b) 2008
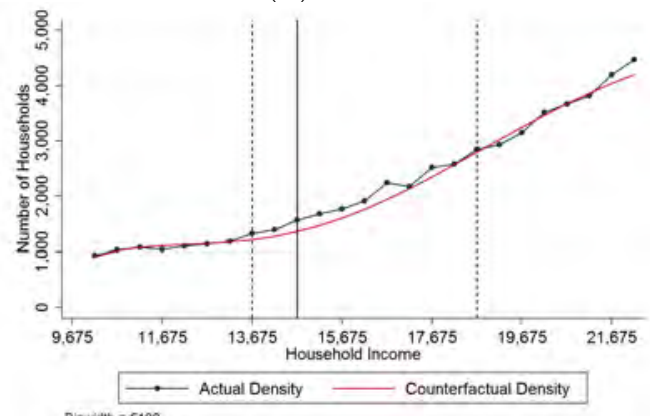

Binwith - E100
Polynomial order

(d) 2010

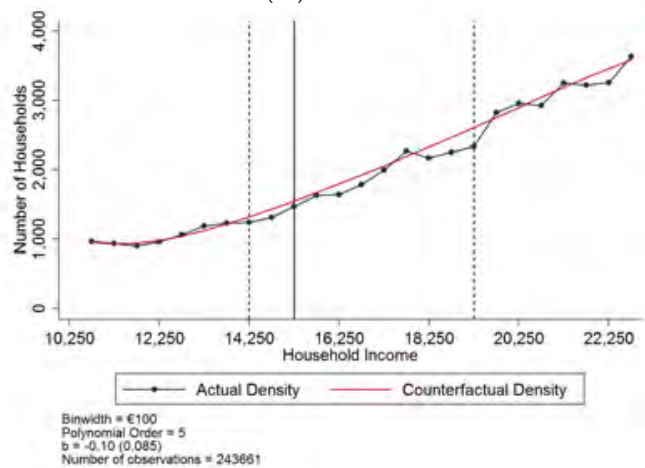

(f) 2012

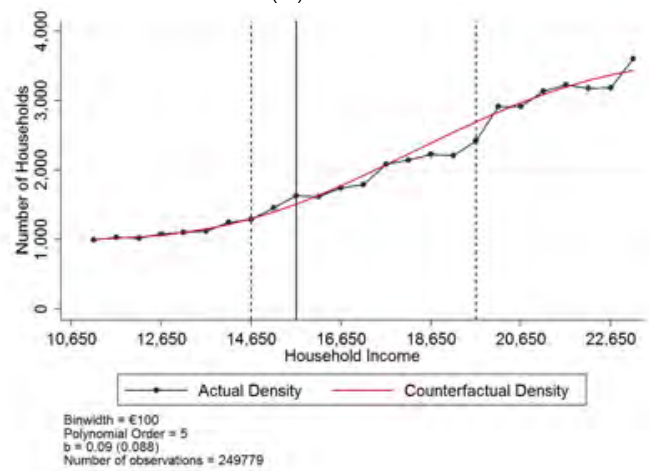

(h) 2014

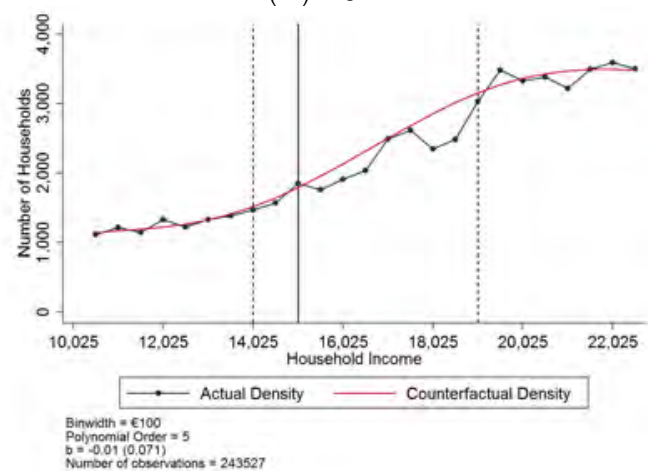


Figure A.3: Income distribution single parents around kink: by single year

(a) 2007

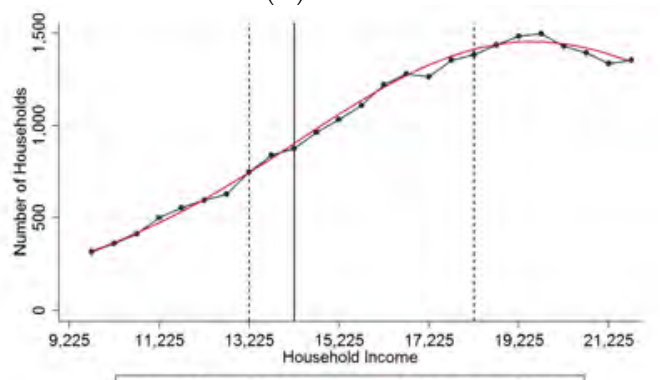

$\longrightarrow$ Actual Density C Counterfactual Density

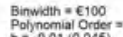

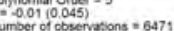

(c) 2009

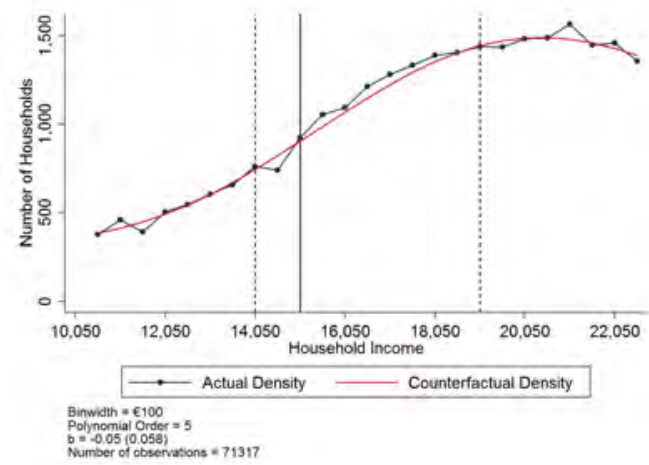

(e) 2011

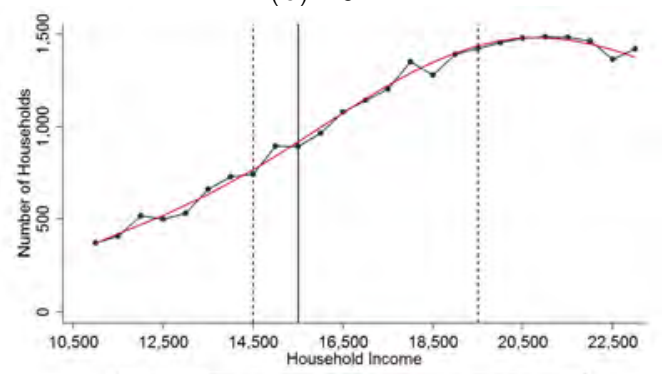

$\longrightarrow$ Actual Density C Counterfactual Density

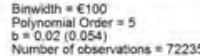

(g) 2013

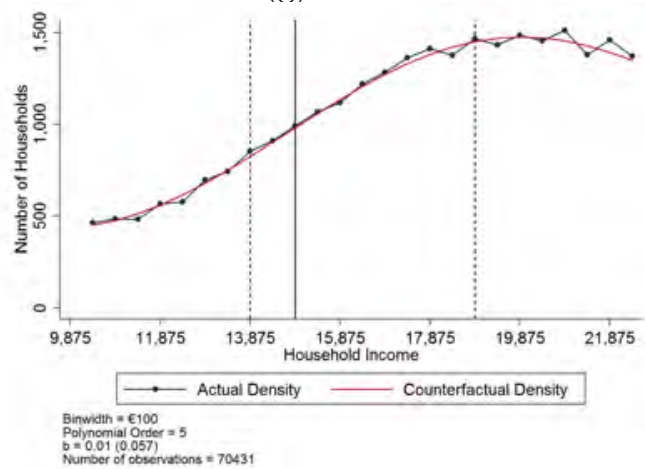

(b) 2008
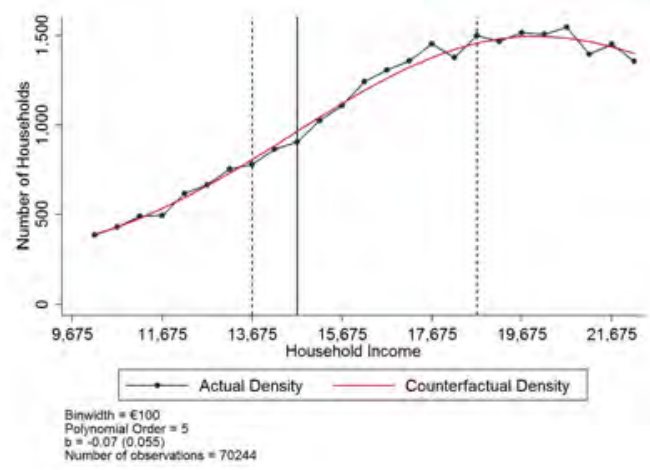

(d) 2010

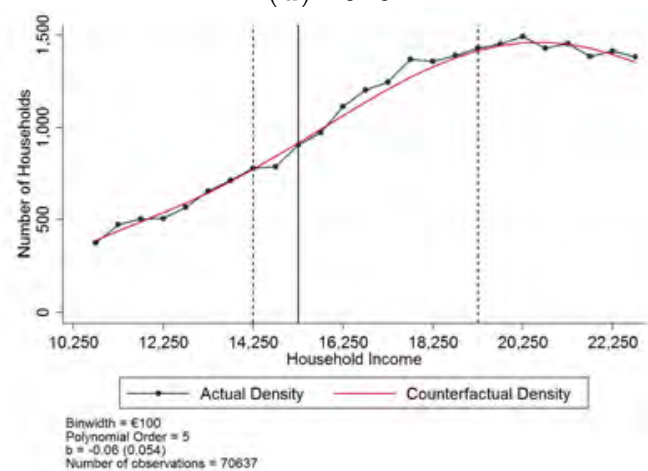

(f) 2012

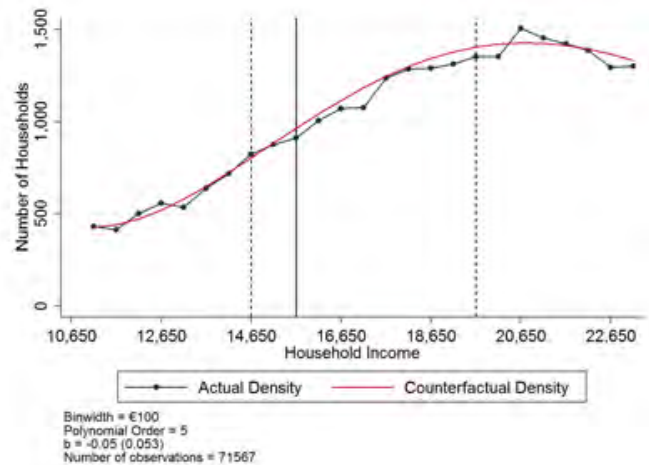

(h) 2014

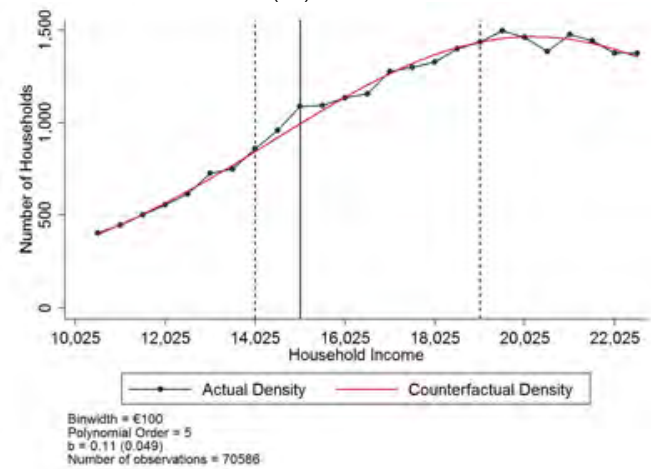


Figure A.4: Income distribution couples w/o children around kink: by single year

(a) 2007

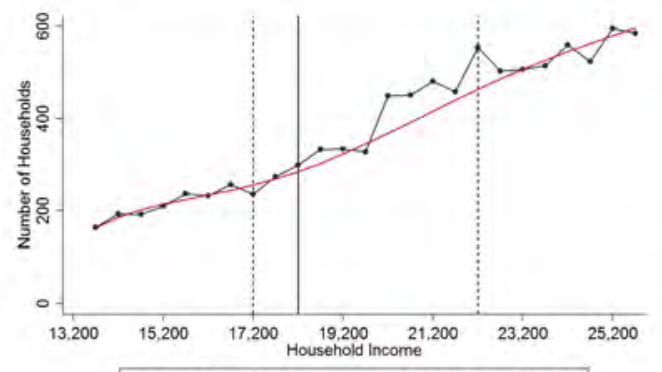

$\longrightarrow$ Actual Density $\longrightarrow$ Counterfactual Density

Binwidth = $\epsilon 100$
Polynomial Order $=$

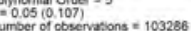

(c) 2009

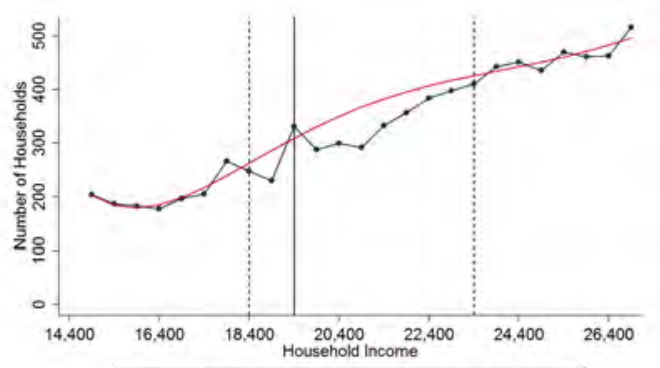

- Actual Density $\longrightarrow$ Counterfactual Density

Binwith $=$ E100
Polynomial Oroder

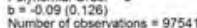

(e) 2011

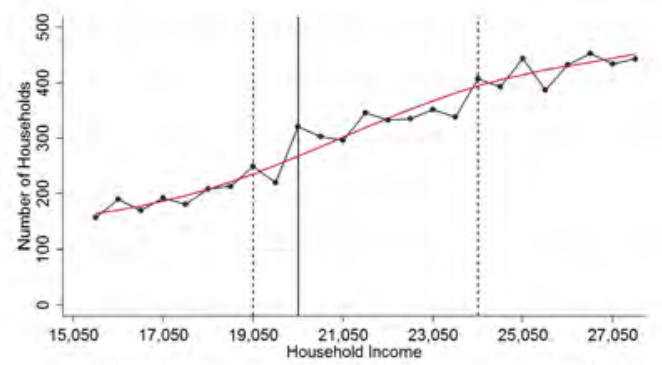

$\longrightarrow$ Actual Density C Counterfactual Density

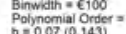

(g) 2013

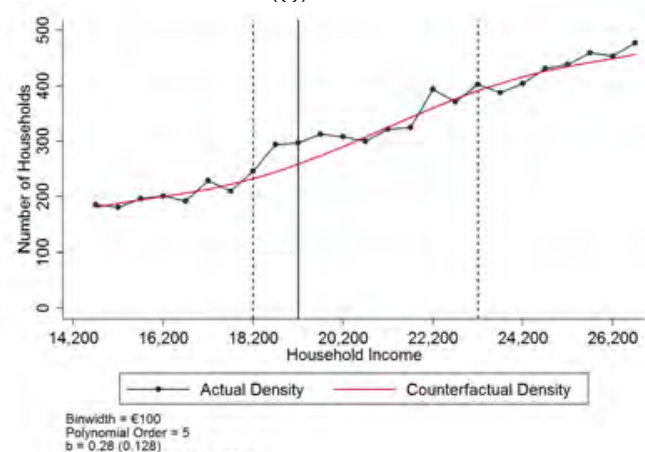

Ponwynomial Order $=5$
$b=0.28(0.128)$

$0.28(0.128)$. (b) 2008

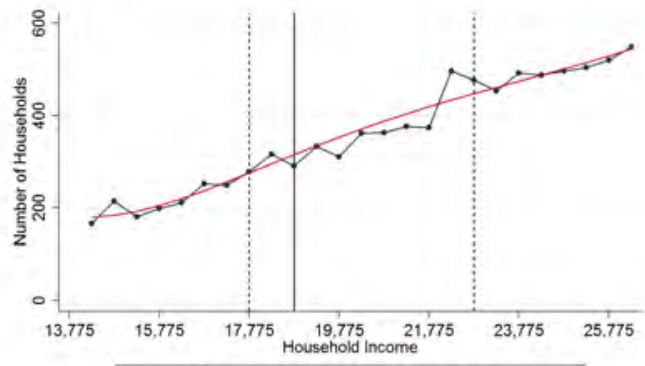

Binwidh $=$ E100
Potyonial Ordes

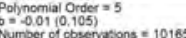

(d) 2010

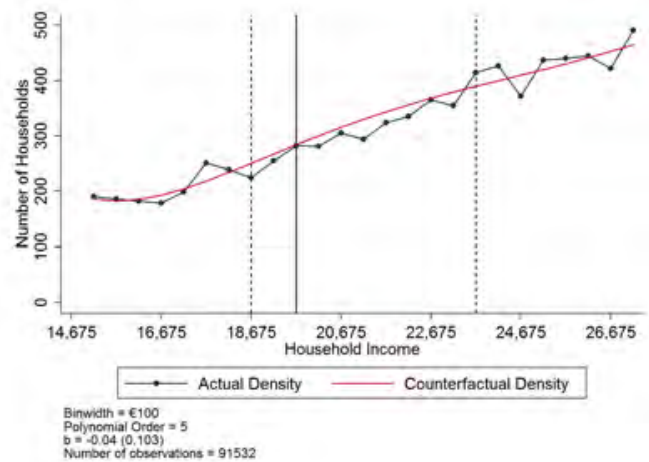

(f) 2012
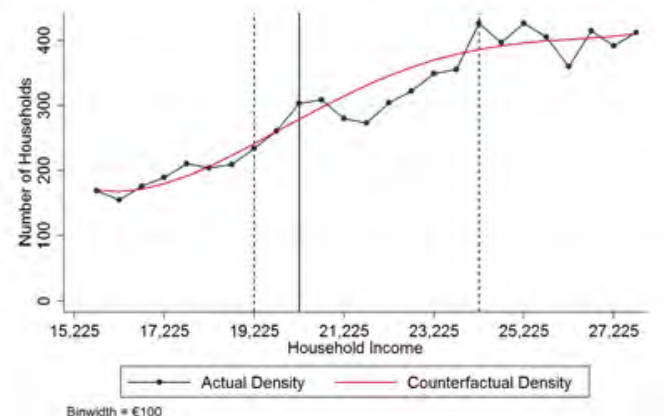

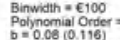

(h) 2014

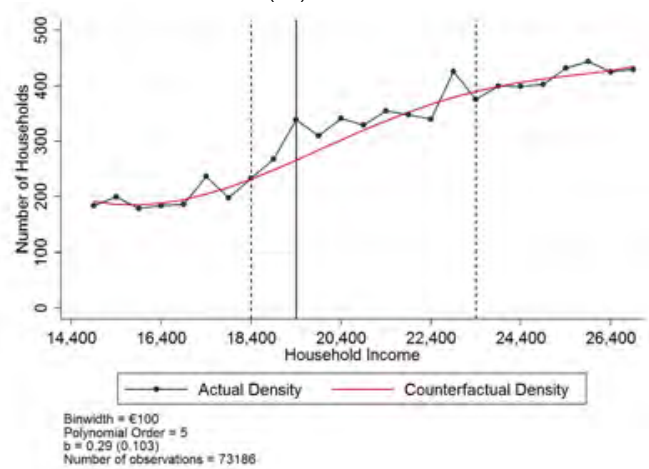


Figure A.5: Income distribution couples with children around kink: by single year

(a) 2007

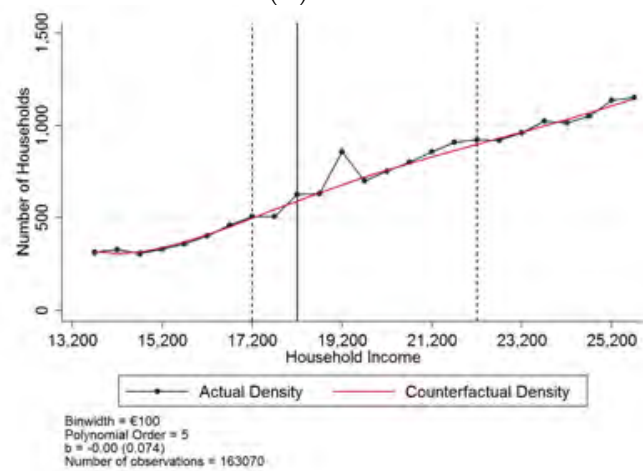

(c) 2009

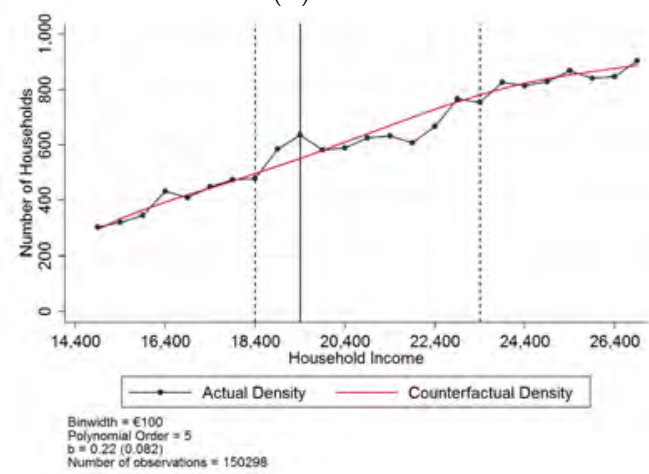

(e) 2011

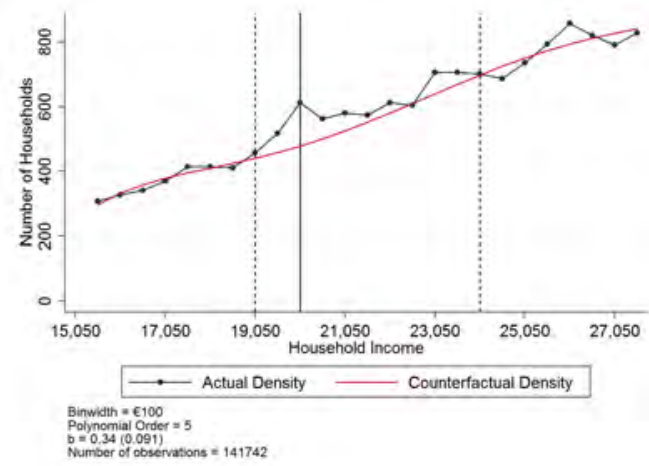

(g) 2013

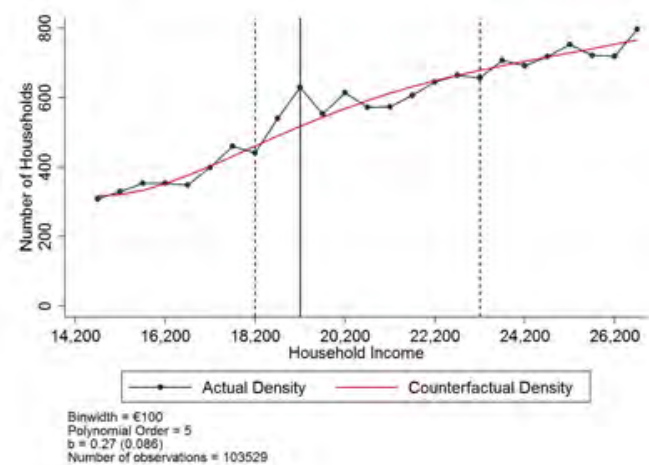

(b) 2008

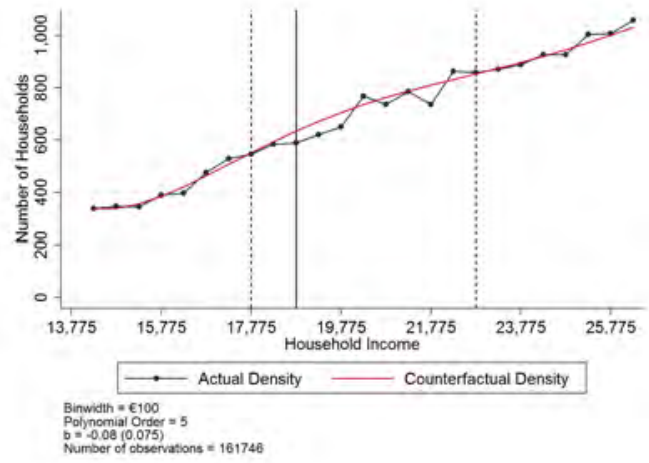

(d) 2010

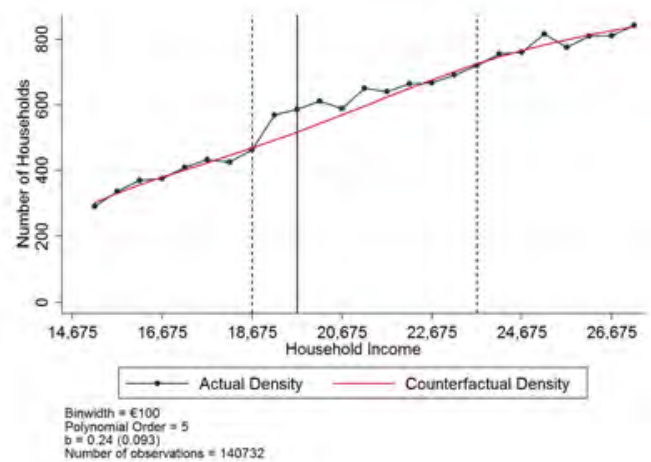

(f) 2012

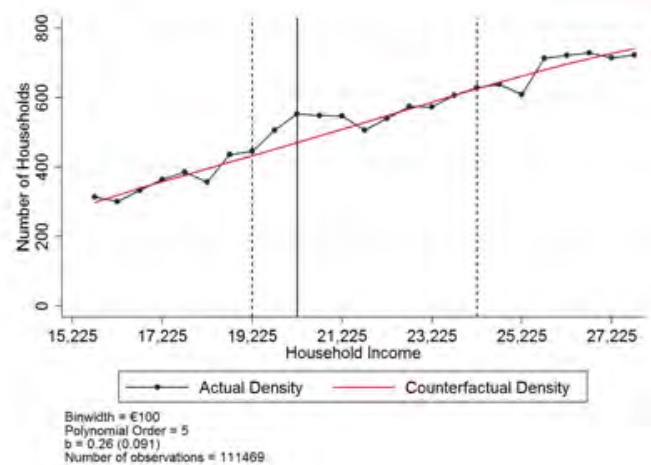

(h) 2014

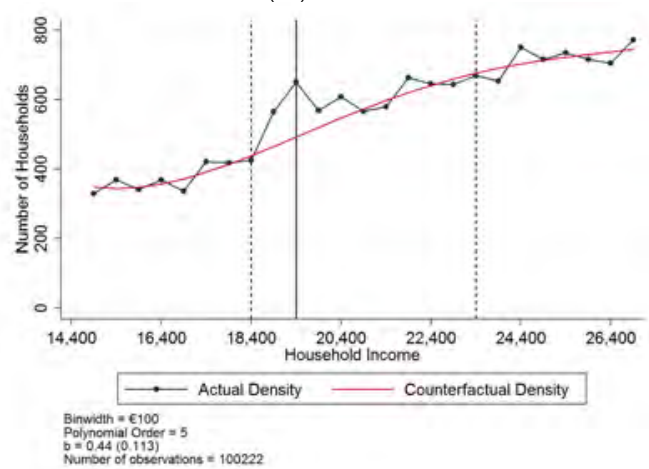


Figure A.6: Income distribution childless singles around notch: by single year

(a) 2007

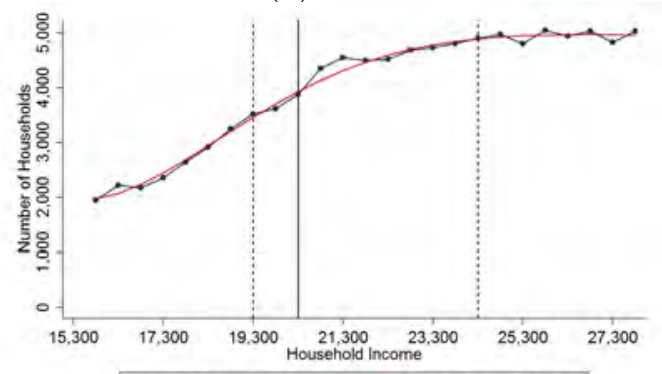

$\longrightarrow$ Actual Density C Counterfactual Density

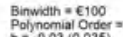

$b=0.03(0.035)$
Number of of chervations $=255883$

(c) 2009

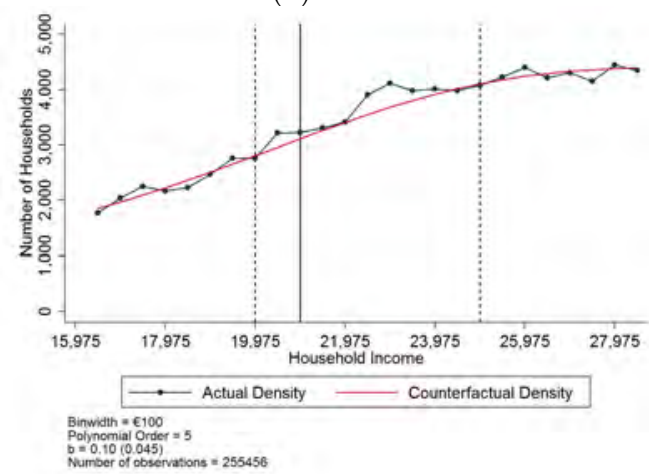

(e) 2011

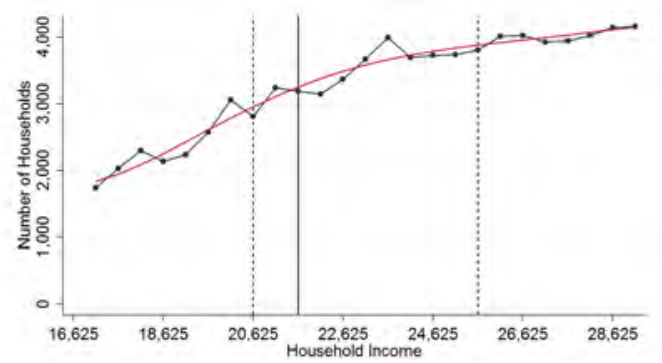

$\longrightarrow$ Actual Density C Counterfactual Density

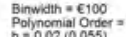

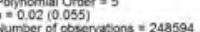

(g) 2013

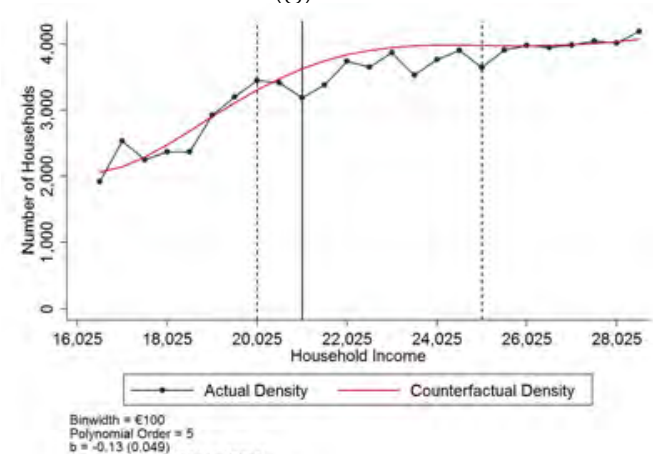

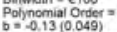

umber of cobsenvations (b) 2008

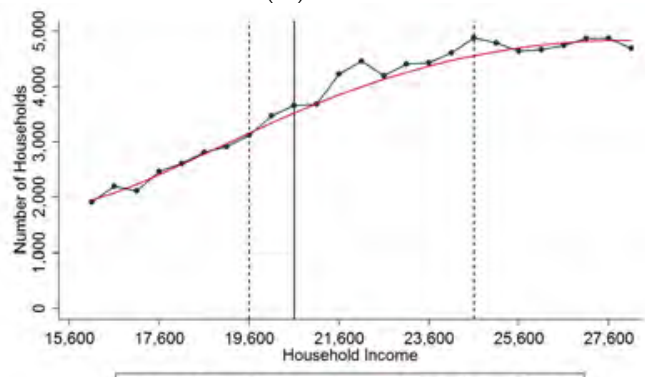

Binwidh = E100
Polynomial Order $=$

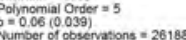

(d) 2010

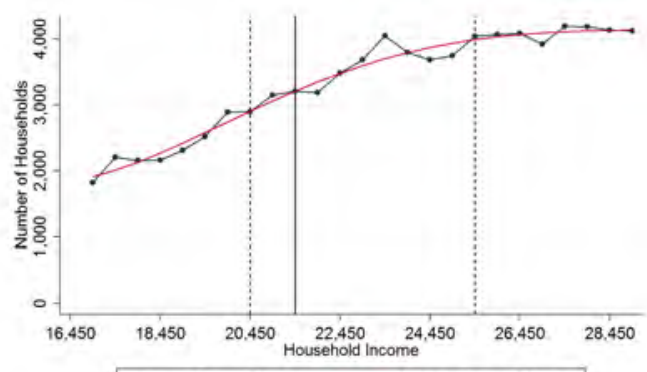

Binwith = E100
Polynomial Order

$b=0.02(10.043)$
Number of observations $=24366$.

(f) 2012

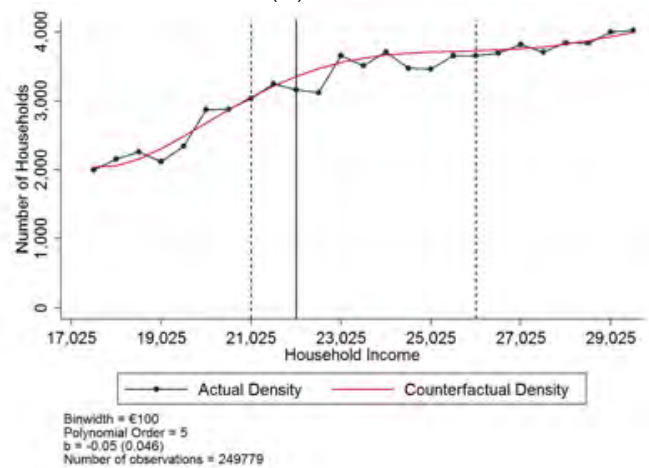

(h) 2014

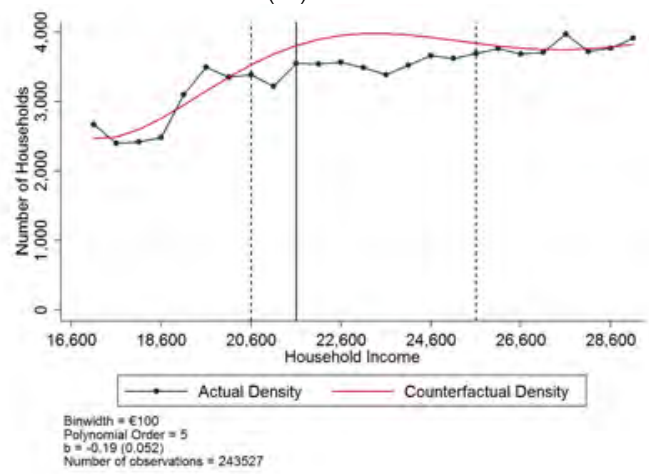


Figure A.7: Income distribution single parents around notch: by single year

(a) 2007

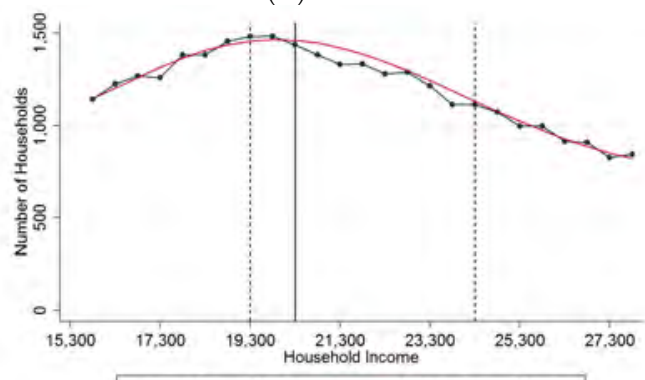

$\longrightarrow$ Actual Density C Counterfactual Density

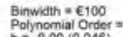

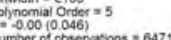

(c) 2009

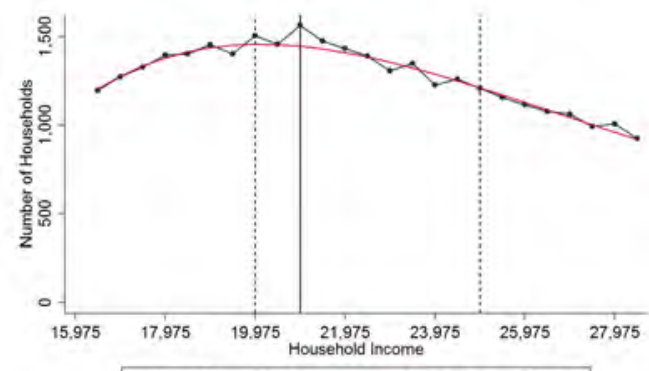

- Actual Density C Counterfactual Density

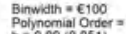

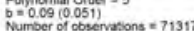

(e) 2011

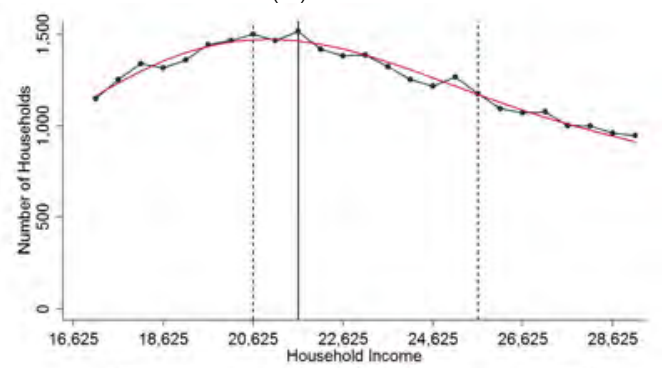

$\longrightarrow$ Actual Density Counterfactual Density

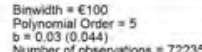

(g) 2013

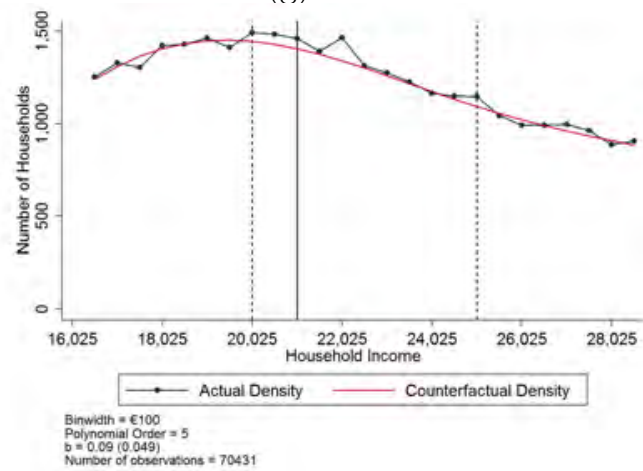

(b) 2008

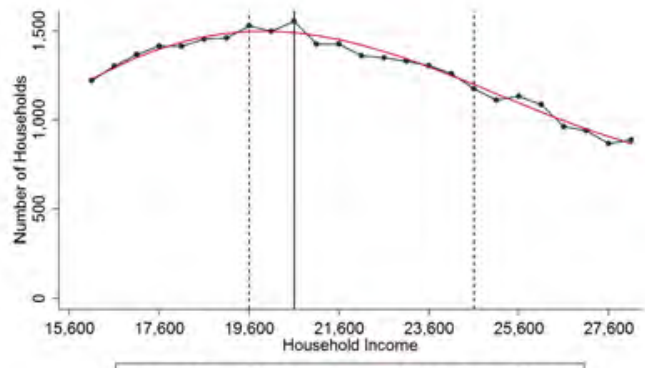

Binwidth $=\epsilon 100$
Polynomial Order $=5$

(d) 2010

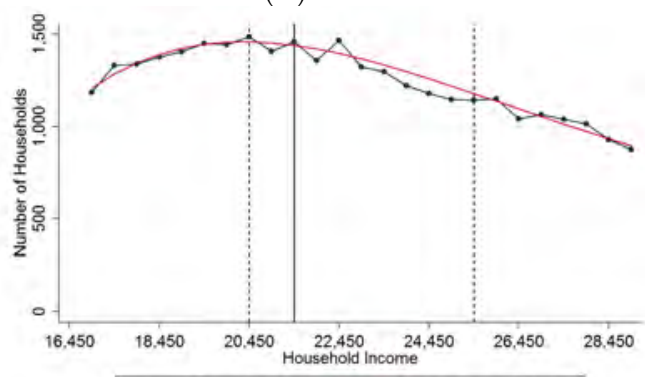

Binwath = E100

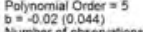

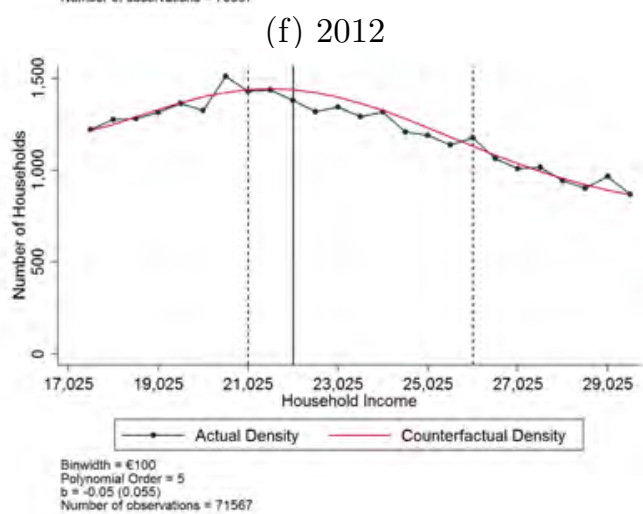

(h) 2014

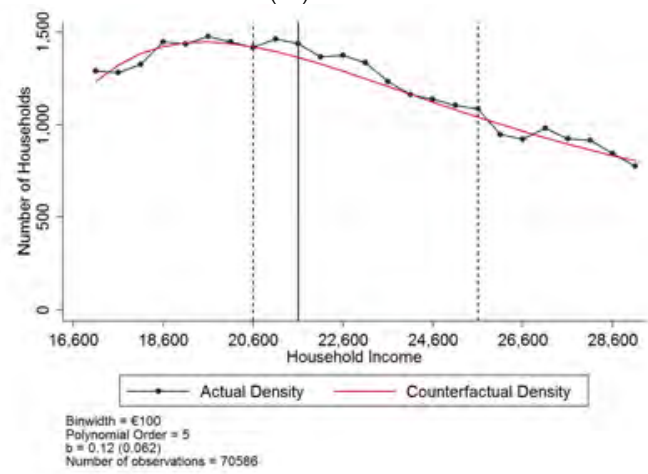


Figure A.8: Income distribution couples w/o children around notch: by single year

(a) 2007

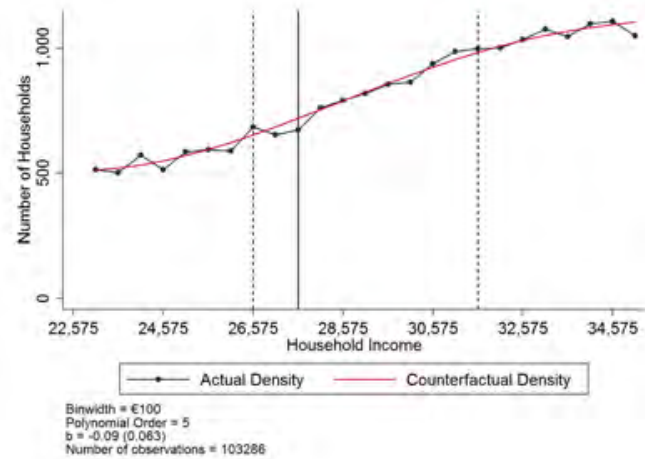

(c) 2009

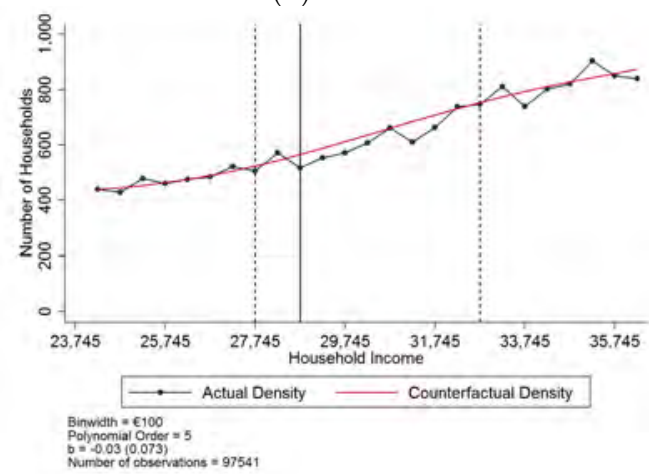

(e) 2011

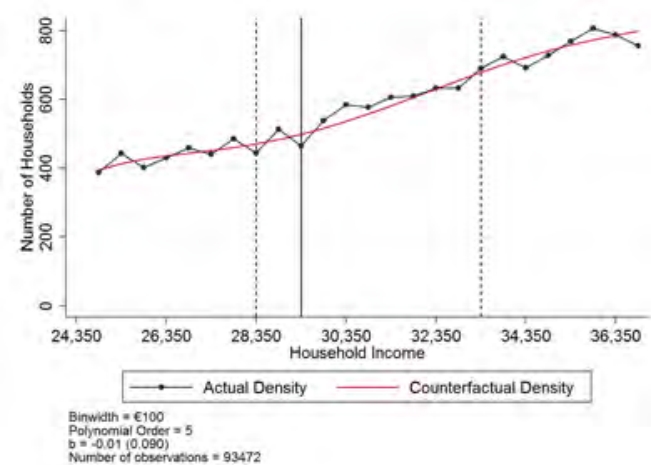

(g) 2013

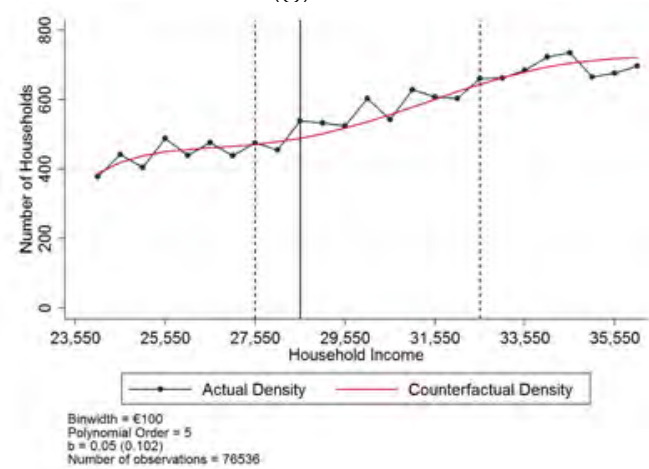

(b) 2008

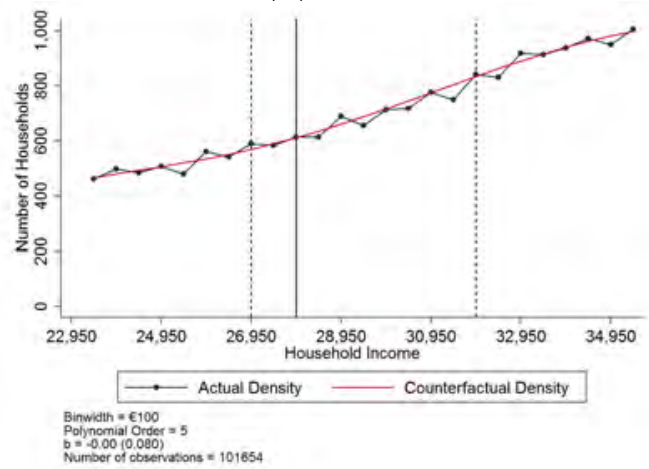

(d) 2010

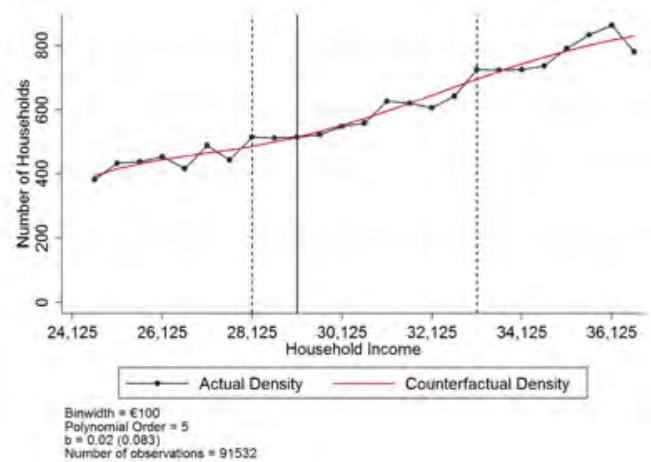

(f) 2012

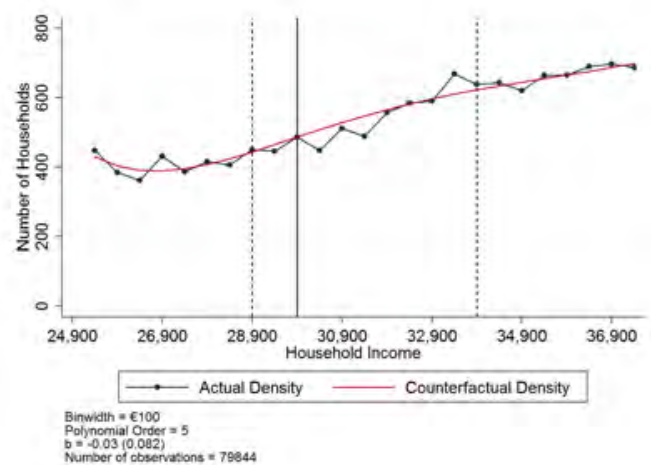

(h) 2014

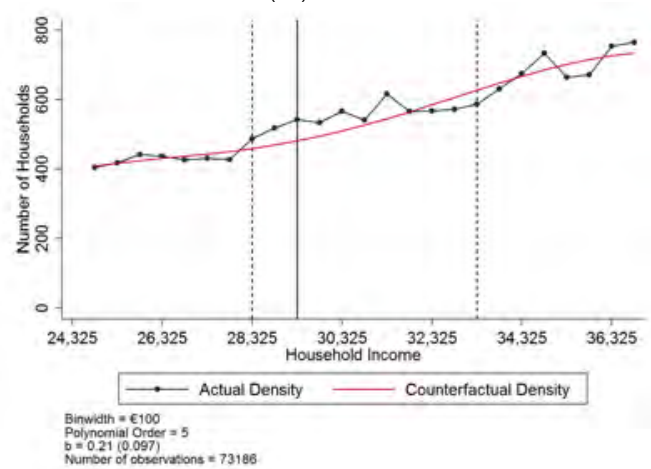


Figure A.9: Income distribution couples with children around notch: by single year

(a) 2007

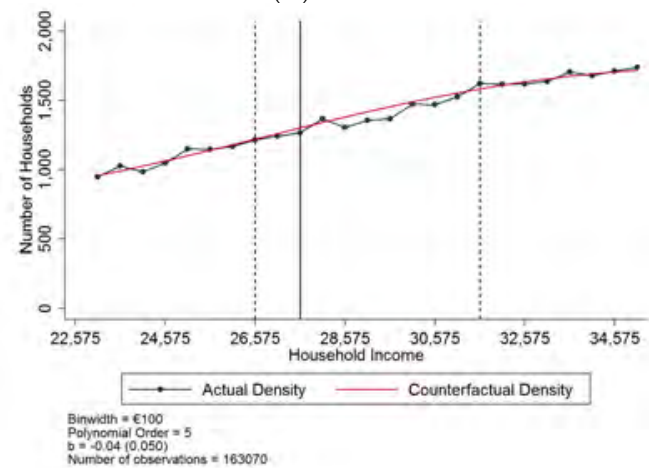

(c) 2009

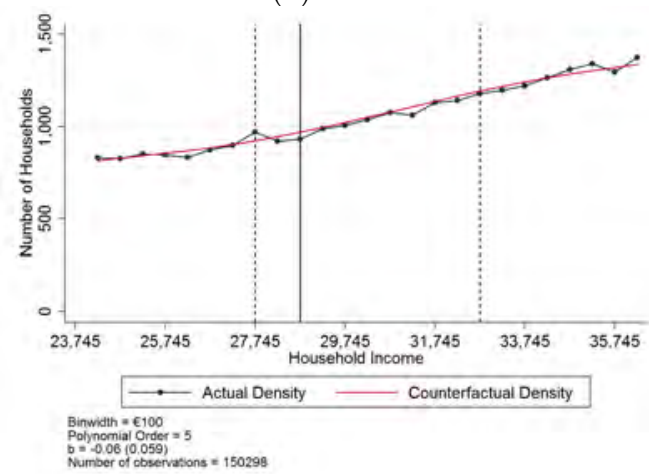

(e) 2011

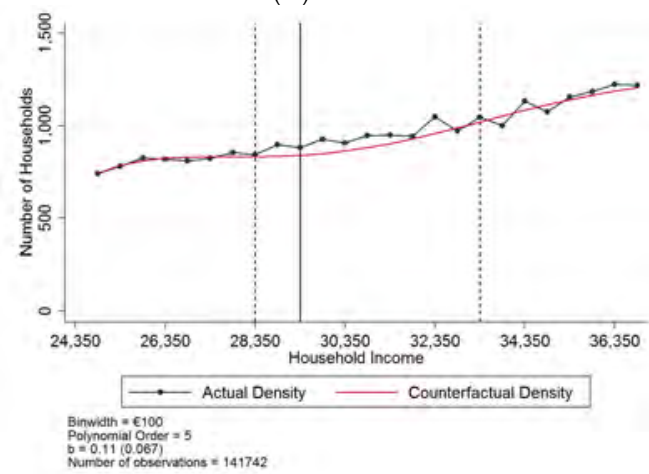

(g) 2013

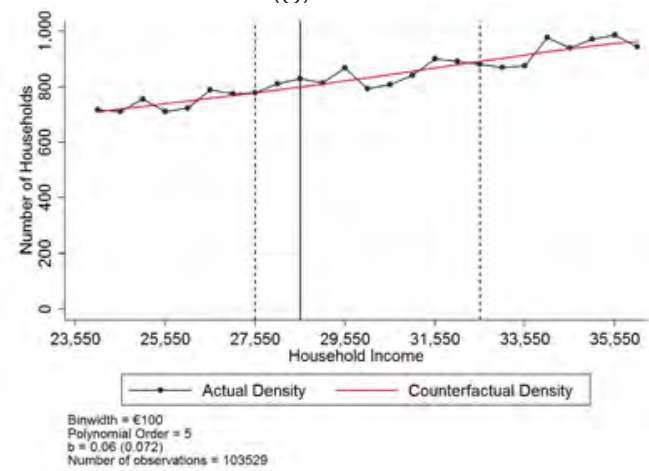

(b) 2008

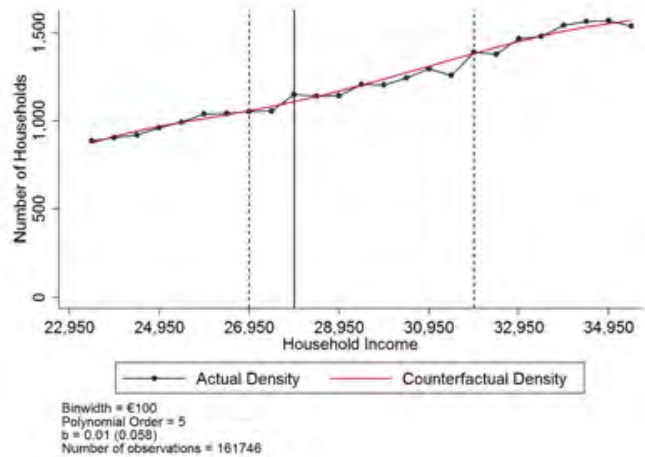

(d) 2010

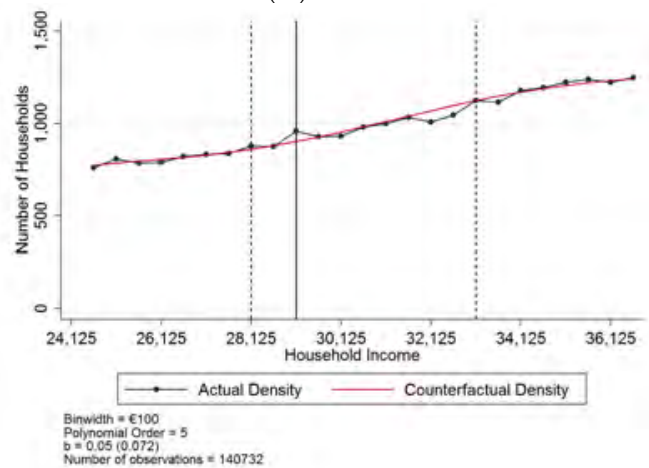

(f) 2012

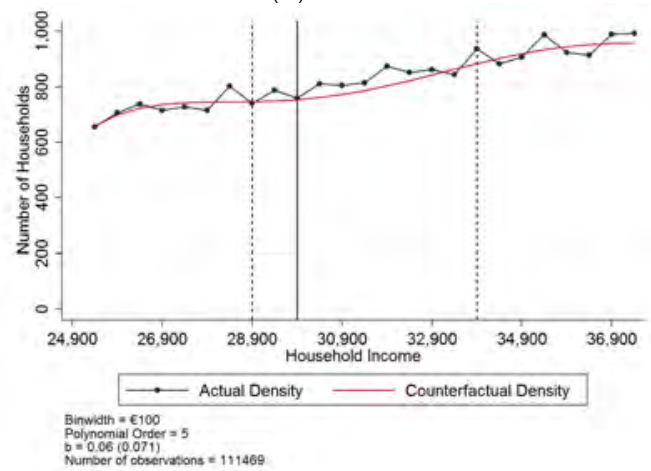

(h) 2014

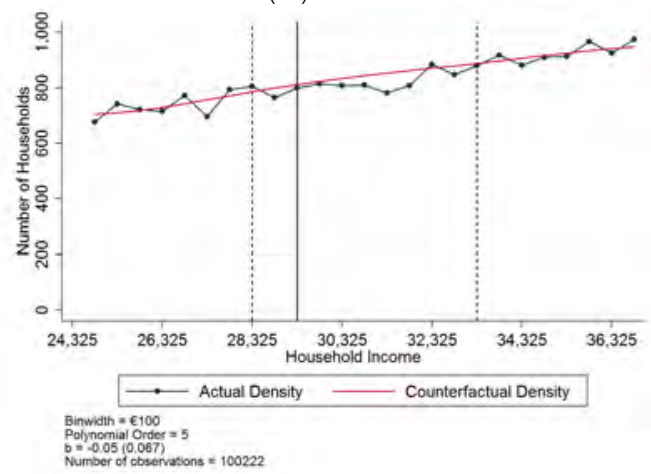


Figure A.10: Bunching at tax bracket thresholds: by household type

(a) Childless singles threshold bracket 1

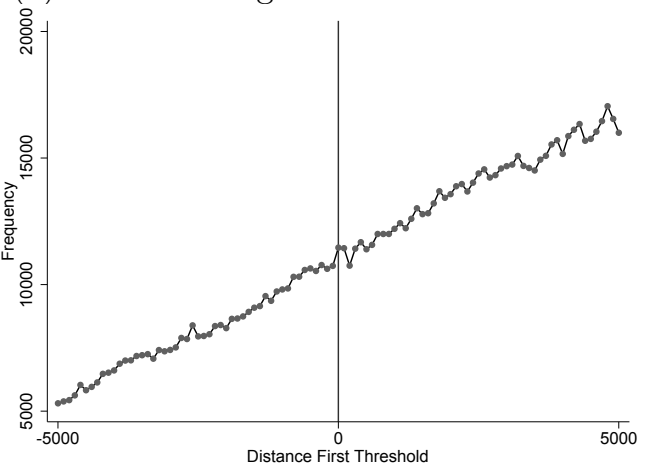

(c) Single parents threshold bracket 1

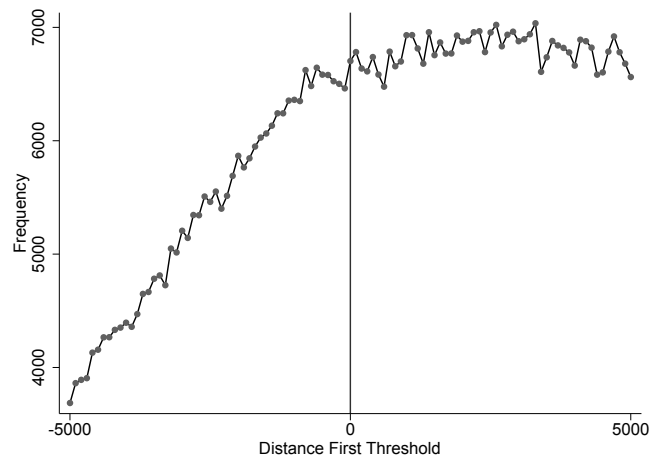

(e) Couples w/o children thresh. bracket 1

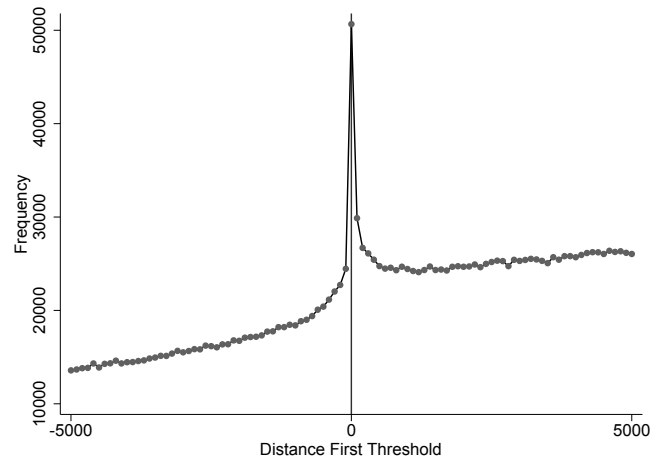

(g) Couples with children thresh. bracket 1

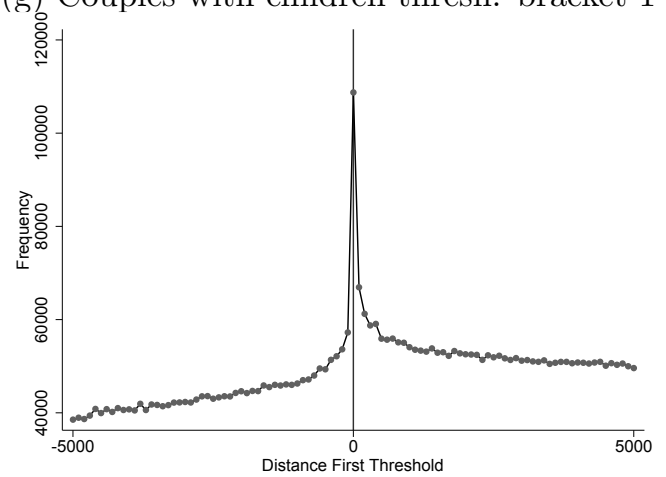

(b) Childless singles threshold bracket 3

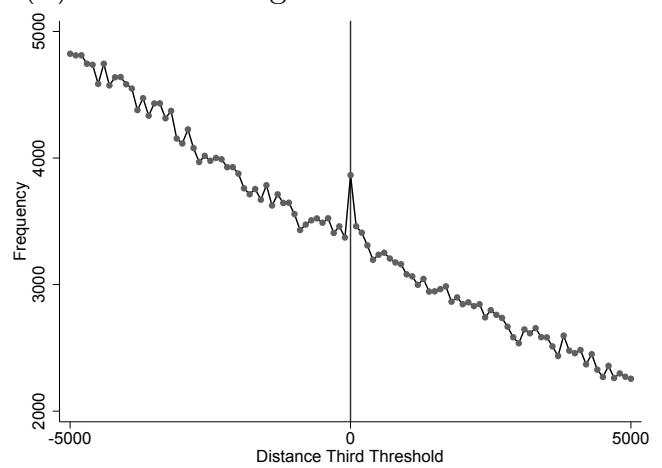

(d) Single parents threshold bracket 3

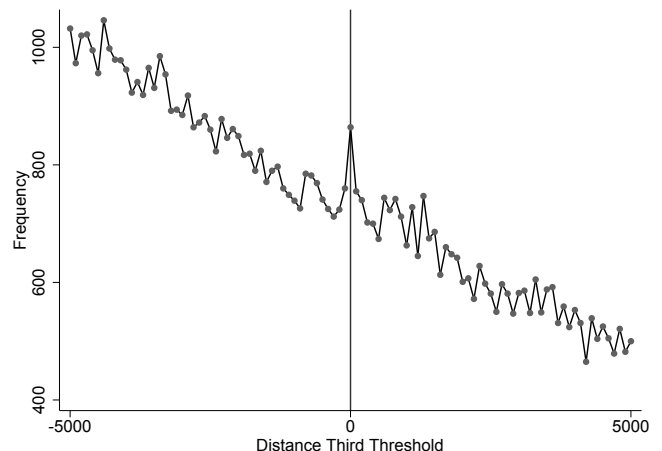

(f) Couples w/o children thresh. bracket 3

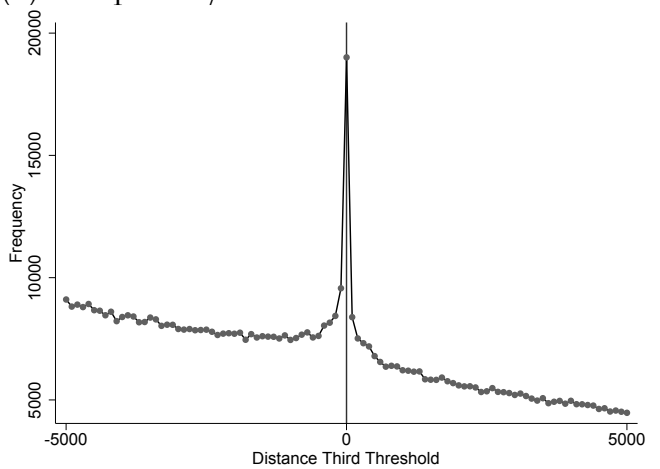

(h) Couples with children thresh. bracket 3

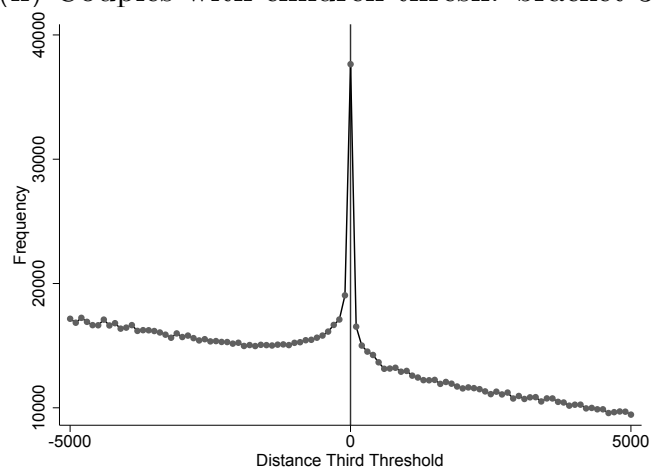


Figure A.11: Bunching at tax bracket thresholds: employees

(a) Childless singles threshold bracket 1

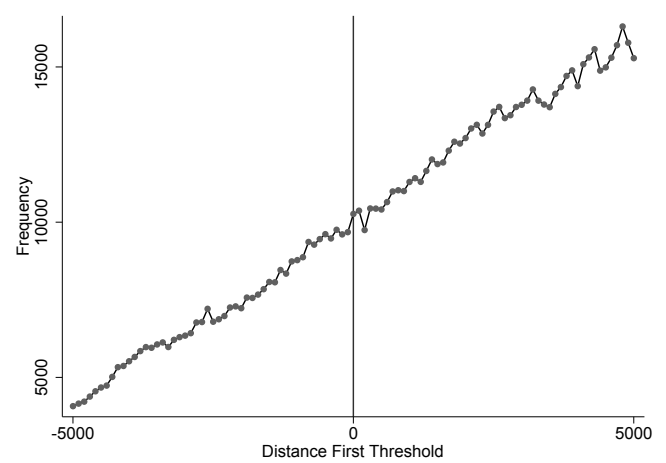

(c) Single parents threshold bracket 1

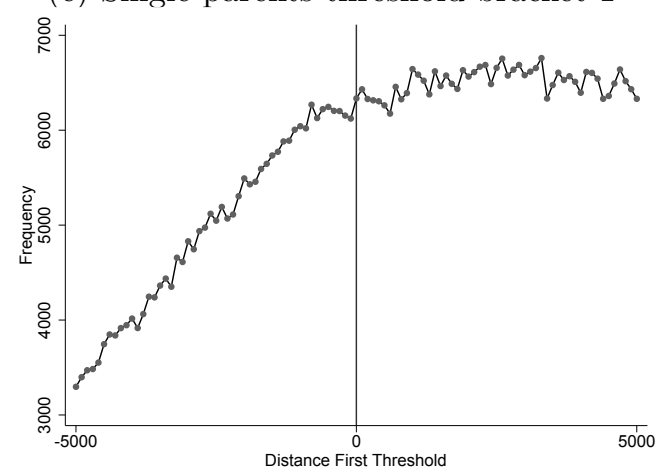

(b) Childless singles threshold bracket 3

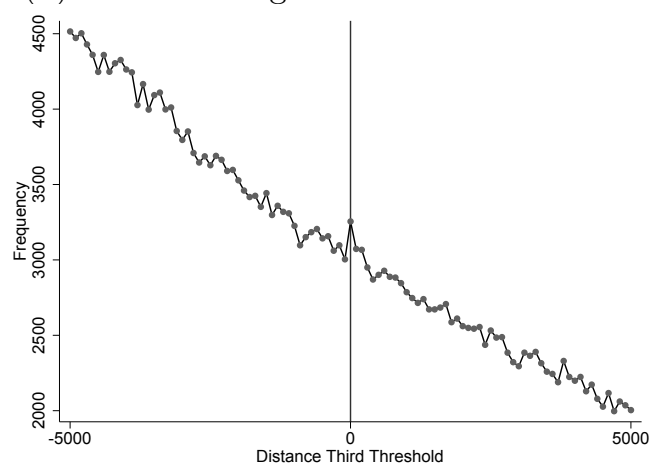

(d) Single parents threshold bracket 3

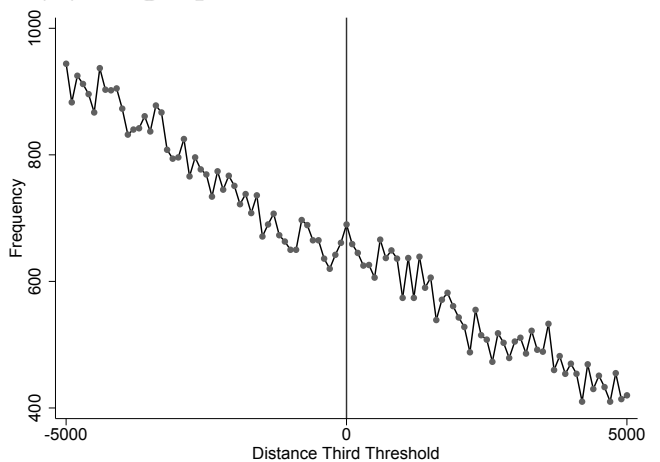

Figure A.12: Bunching at tax bracket thresholds: self-employed

(a) Childless singles threshold bracket 1

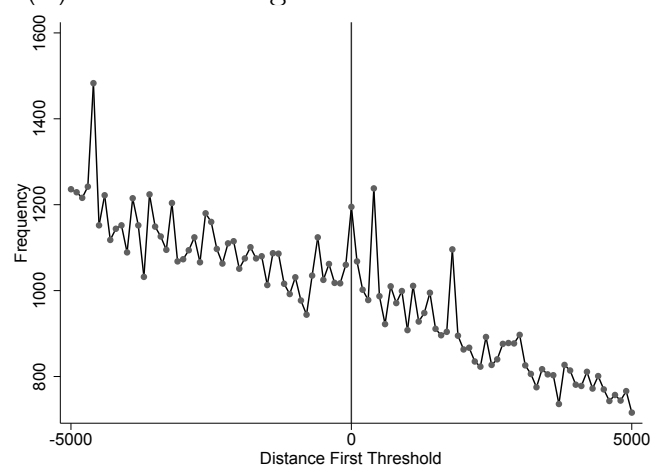

(c) Single parents threshold bracket 1

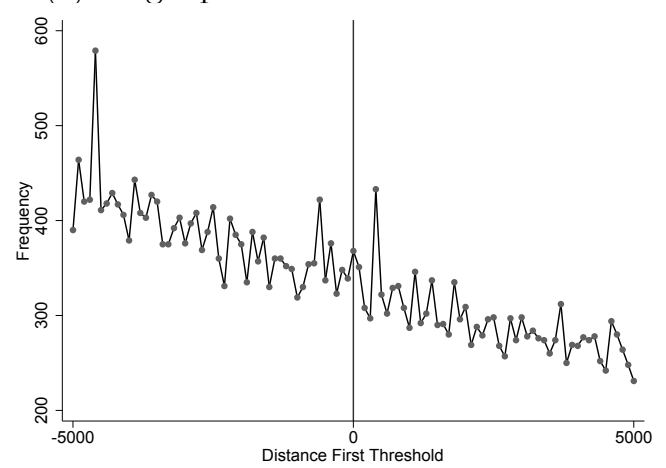

(b) Childless singles threshold bracket 3

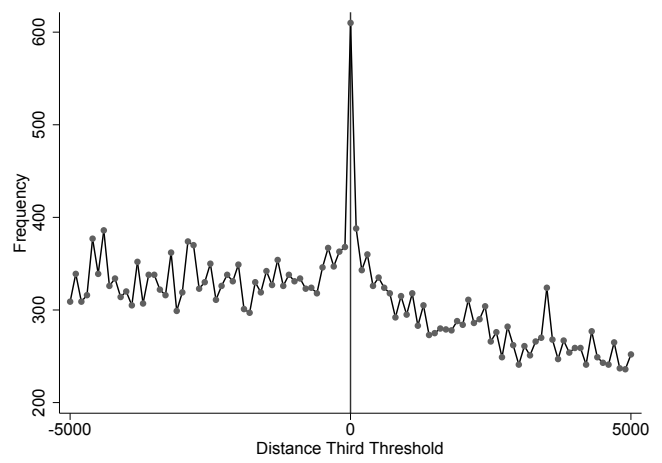

(d) Single parents threshold bracket 3

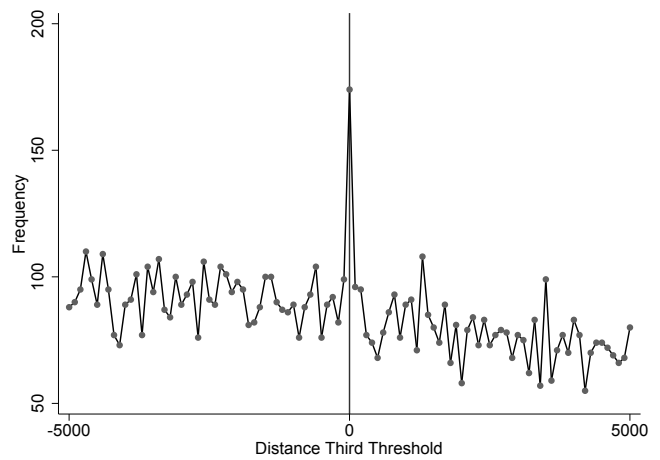


Figure A.13: Bunching at wealth notch childless singles by age

(a) 65- childless singles 2011

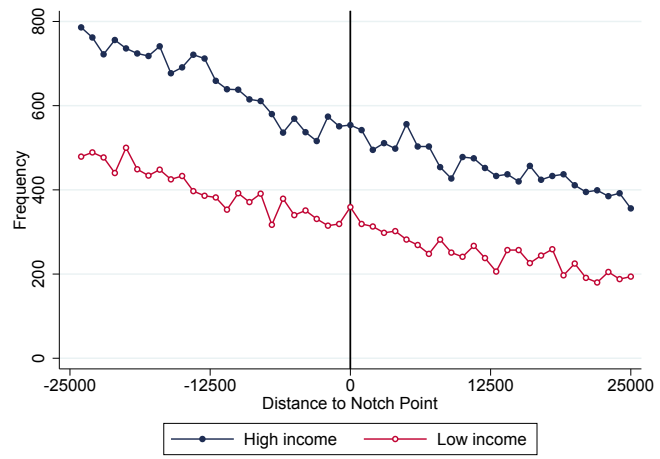

(c) 65- childless singles 2013

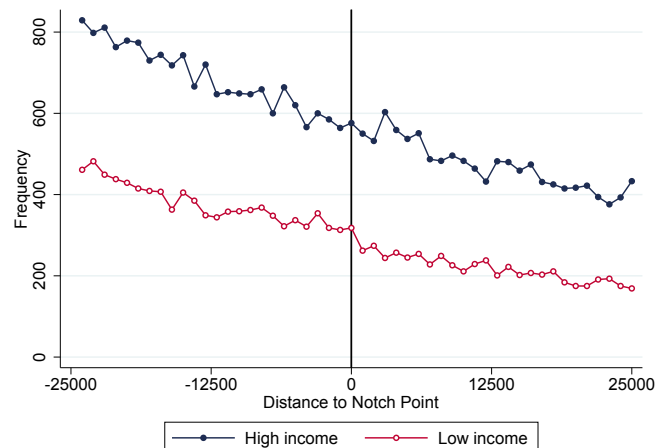

(e) $65+$ childless singles 2011

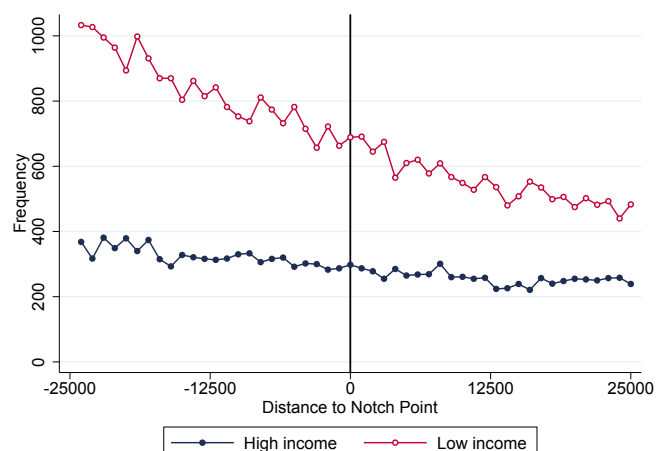

(g) $65+$ childless singles 2013

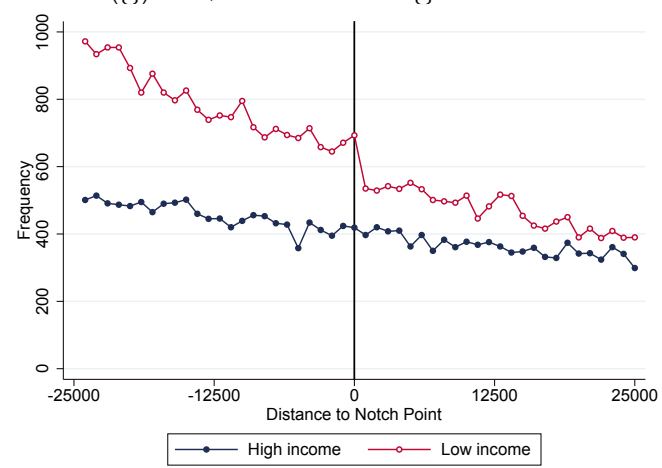

(b) 65- childless singles 2012

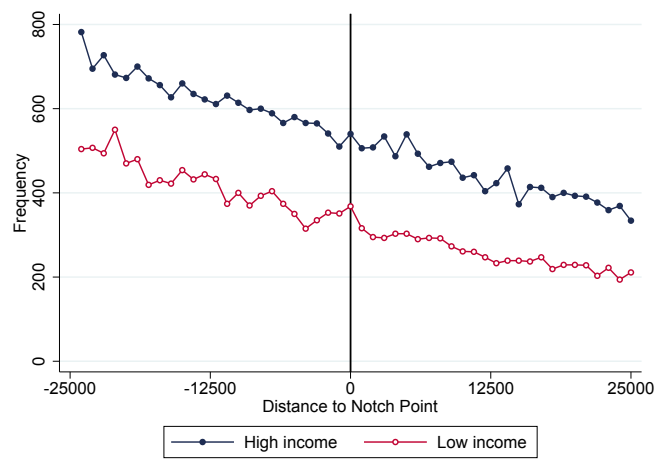

(d) 65- childless singles 2014

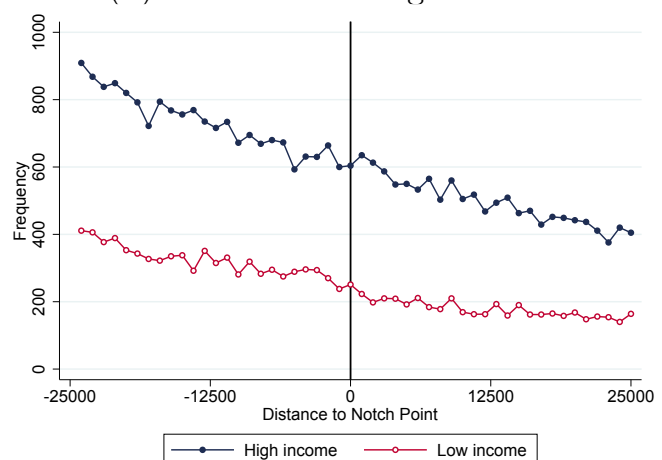

(f) $65+$ childless singles 2012

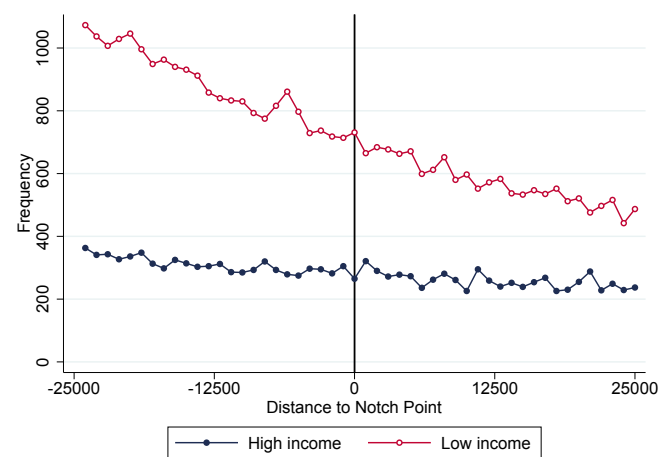

(h) $65+$ childless singles 2014

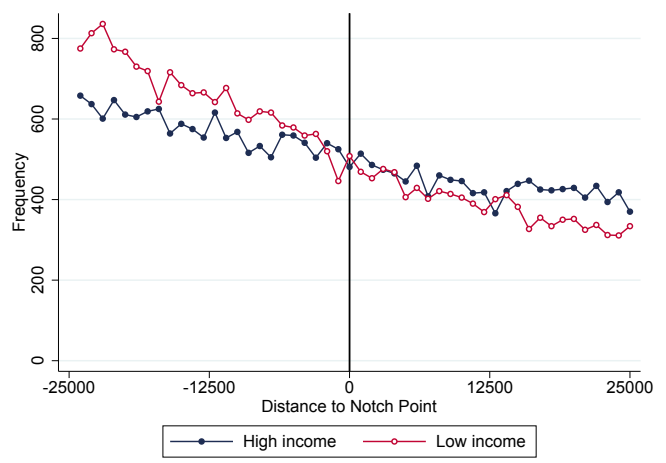


Figure A.14: Daily number of searches on wealth and health care benefits: 2011-2014

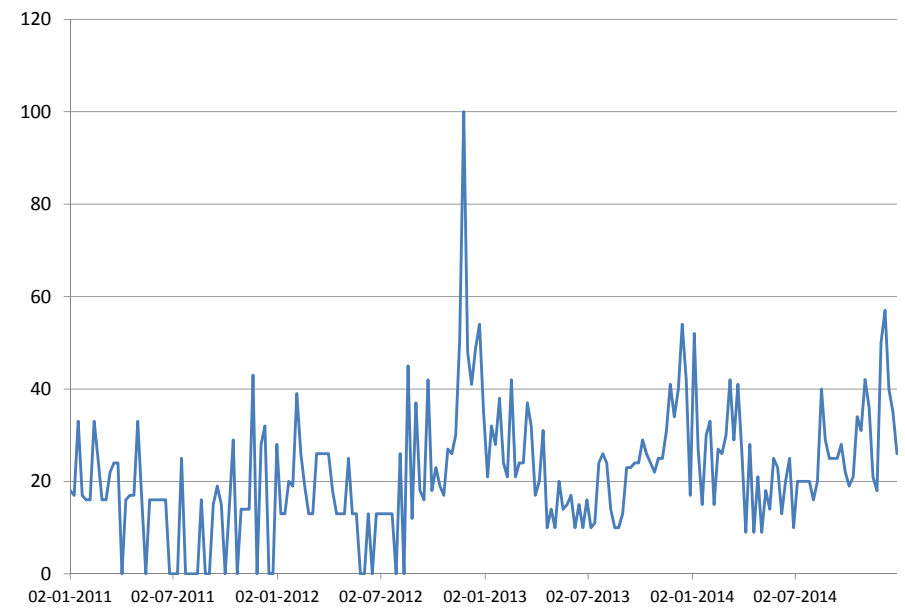

Notes: Daily number of searchers for the terms "vermogen zorgtoeslag" (wealth health care benefits). Source: Google Analytics. 